\title{
An Empirical Analysis of Shopping Behavior across Online and Offline Channels for \\ Grocery Products: The Moderating Effects of Household and Product Characteristics*
}

Junhong Chu, Assistant Professor of Marketing

NUS Business School, 1 Business Link, Singapore 117592

Tel: (65) 6516-6938, bizcj@nus.edu.sg

Marta Arce-Urriza, Ph.D.

Public University of Navarra

marta.arce@unavarra.es

José-Javier Cebollada-Calvo, Associate Professor of Marketing Public University of Navarre, Pamplona, Spain

Tel: (34) 948169736, cebollada@unavarra.es

Pradeep K. Chintagunta, Robert Law Professor of Marketing

University of Chicago Booth School of Business

5807 South Woodlawn Avenue, Chicago, IL 60637

Tel: (773) 702-8015, Pradeep.chintagunta@ chicagobooth.edu

Please, cite as: Chu, J., Arce-Urriza, M., Cebollada, J., \& Chintagunta, P. K. (2010). An Empirical Analysis of Shopping Behavior Across Online and Offline Channels for Grocery Products: The Moderating Effects of Household and Product Characteristics. Journal of Interactive Marketing, 24(4), 251-268. https://doi.org/10.1016/j.intmar.2010.07.004

\footnotetext{
* This project is partially supported by the Singapore Ministry of Education Research Project R-317-000073-113 and the Government of Navarre and the Spanish Ministry of Science Research Project SEC200204321-C02-02. We are very grateful to a Spanish grocery chain for providing us with the data for this study and to the Kilts Center at the Booth School of Business, University of Chicago for financial assistance. We thank Journal of Interactive Marketing editor Dr. Venkatesh Shankar and three anonymous reviewers for their valuable comments and suggestions. The usual disclaimer applies.
} 


\begin{abstract}
We study the moderating effects of household (e.g., shopping frequency) and product (e.g., sensory nature) characteristics on household brand loyalty, size loyalty and price sensitivity across online and offline channels for grocery products. We analyze the shopping behavior of the same households that shop interchangeably in the online and offline stores of the same grocery chain in 93 categories of food, nonfood, sensory and nonsensory products. We find that households are more brand loyal, more size loyal but less price sensitive in the online channel than in the offline channel. Brand loyalty, size loyalty and price sensitivity are closely related to household and product characteristics. Light online shoppers exhibit the highest brand and size loyalties, but the lowest price sensitivity in the online channel. Heavy online shoppers display the lowest brand and size loyalties, but the highest price sensitivity in the online channel. Moderate online shoppers exhibit the highest price sensitivity in the offline channel. The online-offline differences in brand loyalty and price sensitivity are largest for light online shoppers and smallest for heavy online shoppers. The online-offline differences in brand loyalty, size loyalty and price sensitivity are larger for food products and for sensory products.
\end{abstract}

Keywords: brand loyalty, size loyalty, price sensitivity, e-Commerce, online grocery 


\section{INTRODUCTION}

Since the early 1990s, many manufacturers and retailers have incorporated the Internet into their multichannel strategy and devoted considerable resources to building the online channel. Meanwhile, an increasing number of consumers consider the Internet to be an important shopping venue. In 2009, U.S. online retail sales grew $11 \%$, while all retail sales only grew $2.5 \%$ and about 154 million people or $67 \%$ of the online population shopped online, contributing to online retail sales of $\$ 155$ billion, or 6\% of total retail sales (Sehgal 2010a). Forrester Research forecasts that U.S. online sales will keep growing at a 10\% compound annual rate through 2014 to $\$ 250$ billion (Sehgal 2010a). In Western Europe, online retail sales are expected to grow at $11 \%$ per year, going from $€ 68$ billion in 2009 to $€ 114.5$ billion in 2014 (Sehgal 2010b).

The Internet and conventional brick-and-mortar stores each have unique features. The Internet substantially reduces search costs, grants easy access to product and price information and facilitates product comparison. Online shopping involves no travel, product carrying or restrictions on shopping hours, offering greater accessibility, convenience and time saving. But online shopping does not permit physical examination of the products (feel, touch, sample and trial), interpersonal communication or instant gratification, and often incurs shipping and handling costs. In contrast, offline shopping allows physical examination of the products, interpersonal communication and instant gratification, but involves high travel costs and search costs, and often has restrictions on shopping hours, especially in countries with strong labor laws (Grewal et al. 2004). Consumers may use the two channels differently. Some consumers may use physical stores as the primary shopping channel and the Internet as a supplementary channel, whereas others may follow the reverse pattern. Consequently, the same consumers may exhibit different behaviors when shopping across online and offline channels. Therefore, it is important to understand how the same consumers behave at the two channels.

Several researchers have studied consumer behavior across online and offline channels in different contexts (see Table 1 for a comparison and the literature review section for details), but 
they often use two separate samples for online and offline shopping. As pointed out by Shankar, Smith and Rangaswamy (2003), such "between-subject" comparisons cannot eliminate the selfselection explanation for the behavioral differences observed across the two channels, and cannot isolate the effect of the shopping medium on behavior differences. In this paper, we use a unique household panel dataset to study how the same household's brand loyalty, size loyalty and price sensitivity vary across online and offline channels in grocery shopping, and how these behaviors vary with household and product characteristics. Since we observe the same households that shop across online and offline stores, we are able to conduct a "within-subject" comparison, which allows us to isolate the effect of the Internet on consumer behavior from consumer-specific effects (Shankar, Rangaswamy and Pusateri 2001, Shankar et al. 2003). Further, as we observe the entire shopping basket of both packaged goods and perishables, we are able to investigate a large number of vastly different product categories so as to study the effects of product characteristics on channel-specific behavioral differences. As panel households differ substantially in their online shopping frequency, it allows us to examine how online shopping frequency affects online and offline shopping behavior. Additionally, we show how our data enable us to avoid potential endogeneity issues.

\section{$<$ Table 1 about here >}

Our descriptive study of household shopping behavior involves 93 categories of food, nonfood, sensory and non-sensory items (defined below). Consistent with the literature (e.g. Chu et al. 2008), we find the same households are more brand loyal, more size loyal, but less price sensitive in the online channel than in the offline channel. Brand loyalty, size loyalty and price sensitivity are related to household and product characteristics. Light-online shoppers exhibit the highest brand and size loyalties, but the lowest price sensitivity in the online channel. Heavy-online shoppers display the lowest brand and size loyalties, but the highest price sensitivity in the online channel. Moderate online shoppers exhibit the highest price sensitivity in the offline channel. The online-offline differences in brand loyalty and price sensitivity are the largest for light online 
shoppers and smallest for heavy online shoppers. The online-offline differences in brand and size loyalties and price sensitivity are larger for food products than non-food products, and larger for sensory products than non-sensory products. These findings should help retailers make better decisions on product offerings, pricing and targeted promotions in the online and offline stores.

Categories such as books, CDs, PCs and holiday gifts that are typical of online shopping are more ideally suited to a comparison of consumer behavior across online and offline channels. However, given the infrequent purchases of these categories, it is difficult to collect consumer panel data on the purchases of these categories across the two channels. Although online revenues only account for a small fraction of the supermarket industry, many conventional supermarkets do have online operations (e.g., Safeway's www.safeway.com). In the UK, a report by TNS shows that online grocery sales at Tesco and other main retailers surged 35\% in 2008 over the previous year (The Daily Telegraph 2009). The fact that online giant Amazon is now in the grocery business indicates the increasing importance of online grocery shopping. Therefore, using grocery data, while limited to some extent, can still shed light on the channel-specific behavioral differences.

The rest of the paper proceeds as follows. We first review the relevant literature, develop a conceptual framework and derive the various hypotheses. We then describe the data and present the methodology. Next, we report the results and discuss their managerial implications. We conclude the paper with summary of the findings, limitations and directions for future research.

\section{LITERATURE REVIEW}

Researchers have studied consumer behavior across online and offline channels in various contexts, either analytically or using experimental, survey or market data. The general conclusion is that consumers are more brand loyal and more size loyal in the online channel, but their price sensitivity seems to depend on product categories (Table 1).

Bakos (1997) theorizes that price sensitivity would be lower online than offline when qualityrelated attributes are important to consumers. Lal and Sarvary (1999) analyze the online and offline media and find that the Internet may lead to monopoly pricing under some circumstances. 
Lynch and Ariely (2000) use experiments to study how search costs affect online and offline competition and find that lower search costs for quality information reduce price sensitivity, while lower search costs for price information increase price sensitivity. Brynjolfsson and Smith (2000) find consumers are more price sensitive when shopping books and CDs online than offline. Degeratu, Rangaswamy and Wu (2000) and Andrews and Currim (2004) find online consumers are less price sensitive when shopping groceries online than offline. Both studies find households have less brand switching and size switching online than offline, implying higher brand loyalty and size loyalty online. Danaher, Wilson and Davis (2003) find high market share brands enjoy a loyalty advantage in the online store, while low market share brands enjoy greater brand loyalty in the offline stores.

In all these studies, the online and offline customers come from two separate samples; therefore, the observed differences in shopping behavior may not be caused by the shopping media, but by differences across consumers i.e., the between-subject design could suffer from the selection problem. Shankar et al. (2001) use survey data from the hospitality industry to study the main and moderating effects of the online medium on price sensitivity and find that the online medium does not have a main effect on price importance, but it does increase price search behavior. Shankar et al. (2003) compare customer satisfaction and loyalty in online and offline environments in the lodging service industry and find that consumers exhibit higher loyalty to the service provider when the service is chosen online than offline. Both studies compare online consumers with offline consumers as well as the same consumers' online and offline behavior, thus they are able to rule out the self selection bias in the findings. Our study is also based on a within-subject comparison, but it uses household panel data of actual purchases and focuses on the moderating effects of household and product characteristics.

Chu et al. (2008) compare the same households' price sensitivity across online and offline channels for grocery products and find the same households are less price sensitive in the online channel. Pozzi (2008) investigates the same household's differences in product exploration of 
grocery items across online and offline stores and finds product exploration is systematically more prevalent in the physical stores than it is online, which implies the same consumers may be more inertial in the online channel and thus may show higher brand and size loyalty and less price sensitivity. But these two studies do not directly compare a household's brand loyalty and size loyalty across online and offline channels. Further, all existing studies are limited to a small number of product categories, and thus are not able to systematically investigate the effects of household and product characteristics on the differences in channel-specific shopping behavior.

In sum, existing literature provides us with a good foundation for comparing online and offline shopping behaviors for grocery products. However, not much is known about the moderating effects of household and product characteristics on the behavioral differences across the online and offline channels. Our paper intends to address this issue.

\section{CONCEPTUAL FRAMEWORK AND HYPOTHESES}

The same households are found to be more brand loyal, more size loyal and less price sensitive when shopping grocery products in the online channel than in the offline channel (Chu et al. 2008, Pozzi 2008). How are their brand and size loyalties and price sensitivity affected by their online shopping frequency? How do these behaviors differ across product categories? In this section, we develop hypotheses on the effects of household and product characteristics on the shopping behavior differences across the two channels.

The Moderating Roles of Household Characteristics in Within-channel Brand and Size Loyalties and Price Sensitivity

Households are found to be more brand loyal, more size loyal and less price sensitive in the online store than in the offline stores. If it is Internet, the shopping medium per se that makes consumers more brand loyal, more size loyal and less price sensitive, a logical conclusion will be that the more a household shops online, the more brand loyal and size loyal and the less price sensitive it will be in the online store. However, it is the combination of the particular circumstances (e.g. time pressure), the household's particular needs (e.g. convenience and time 
saving), and the web design (personal shopping lists) that makes the household more brand loyal, more size loyal and less price sensitive (Chu et al 2008, Pozzi 2008). We believe the particular circumstances and the particular needs are the primary factors and web design is only a facilitator. If a household is not subject to time pressure, or not seeking convenience or time saving, a rational response will be to do more in-store search to get better deals. Putrevu and Ratchford (1997) find that time pressure is negatively related to search. Therefore households that use the Internet sparingly or selectively for their grocery shopping are more likely to show strong brand loyalty, size loyalty and weak price sensitivity in the online store because the infrequent visits to the online store are more likely to occur during special circumstances.

Households may use the online and offline stores differently for grocery shopping, i.e. they have different levels of involvement with the online channel and the offline channel. Some households may view the physical stores as the primary shopping channel and the online store as the supplementary channel, so they have low-involvement with the Internet channel (light online shoppers). Some households may view the online store as the primary channel and the physical stores as the supplementary channel, so they have high-involvement with the online channel (heavy online shoppers). Some households may treat the two roughly equally and shop in the more "economical" outlet, so they have moderate-involvement with the online channel (moderate online shoppers). Studies have shown that purchase involvement influences brand commitment, loyalty and price sensitivity (e.g. Morrison 1979, Taylor 1984, Beatty, Homer and Hahle 1988, Warrington and Shim 2000). Cheema and Papatla (2009) find Internet experience affects the relative importance of online and offline information and purchase behavior. Light online shoppers may visit the online store only in some special circumstances such as under extreme time pressure. In such circumstances, they will be least likely to do in-store search, most likely to use the customized lists, and most willing to pay a price premium for the convenience and time saving (Putrevu and Ratchford 1997). Since they do not shop much in the online store, they have little incentive to search because they do not benefit much from intensive search. Therefore, they 
will be more brand loyal, more size loyal and less price sensitive in the online store. Because light online shoppers primarily shop offline, they benefit more from search in offline stores, and thus show higher price sensitivity in offline stores.

On the other hand, heavy online shoppers are highly involved with the Internet channel. They view the Internet as the primary channel and the physical stores as the supplementary channel. They shop at the Internet store regularly, but only visit the physical stores on special circumstances such as when they run out of certain categories. Depending on the particular shopping occasion, they may search within the store, or simply use the shopping lists. But since these households primarily shop online, more in-store search will help them save more in the online store. Moreover, these households are experienced online shoppers and know the online store layout very well. Studies have found familiarity with the store facilitates search behavior (Park, Iyer and Smith 1989). Thus, heavy online shoppers can easily find out better deals in the online store. The various online features may still make them less price sensitive in the online store than in the offline stores, but they may be more price sensitive in the online store than light online shoppers. Since they do not visit the physical stores regularly, they do not benefit much from intensive search there; or they only visit the physical stores on special circumstances and are not able to search around. Therefore, they will be less price sensitive in the offline stores than light online shoppers.

Moderate online shoppers may consider these two channels as close substitutes, and go to whatever store that has a better deal. Even though their online behavior is somewhat constrained by the limited number of online grocers and by the web design, their offline shopping behavior can exhibit more latitude in terms of search and comparison. Therefore, they may show the highest price sensitivity in the offline stores. Consequently, we expect the light online shoppers to be the least price sensitive and the heavy online shoppers to be the most price sensitive in the online store, and the moderate online shoppers to be the most price sensitive and the heavy online shoppers the least price sensitive in the offline stores. Therefore we hypothesize: 
H1: Light online shoppers are more brand loyal than heavy online shoppers in the online store.

H2: Light online shoppers are more size loyal than heavy online shoppers in the online store.

H3a: Light online shoppers are the least price sensitive in the online store.

H3b: Heavy online shoppers are the most price sensitive in the online store.

H3c: Moderate online shoppers are the most price sensitive in the offline stores.

H3d: Heavy online shoppers are the least price sensitive in the offline stores.

Moderating Roles of Household Characteristics in Online-Offline (between-channel) Behavioral Differences

The panel households are all mixed shoppers who shop in both channels. They differ in observed demographics, but the differences are not dramatic. Thus, brand loyalty and size loyalty between adjacent groups such as between light and moderate online shoppers, or between moderate and heavy online shoppers may not differ substantially. Since light and heavy online shoppers are expected to exhibit very different behavior in the two channels, from $\mathrm{H} 1$ to $\mathrm{H} 3$ we deduce that:

H4: Differences in online and offline brand loyalty are largest for light online shoppers and smallest for heavy online shoppers.

H5: Differences in online and offline size loyalty are largest for light online shoppers and smallest for heavy online shoppers.

H6: Differences in online and offline price sensitivity are largest for light online shoppers and smallest for heavy online shoppers.

\section{Moderating Roles of Product Characteristics in Online-offline Behavioral Differences}

Product characteristics such as food versus non-food, sensory versus non-sensory may affect consumer shopping behavior differently in the online store from the offline stores. Food products, particularly perishables, have higher quality uncertainty than non-food items. The purchase of food products involves an additional risk over non-food products - the health risk. To reduce 
quality uncertainty and avoid health risk, consumers may resort to brand names (Wernerfelt 1988, Png and Reitman 1995). This is particularly true for online shopping because (1) they cannot physically examine the products before purchase, and (2) it might be difficult to find some important information such as the "sell by date", which might be missing or put at the corner of the pack. When shopping for food items in a physical store, consumers can carefully examine the sell-by date and compare quality (Tsiros and Heilman 2005), thus there is less need to rely on the brand for quality assurance. Kacen et al (2002) find consumers perceive the quality of food products to be better in physical stores than in online stores and are less uncertain about getting the right product when shopping offline. Consequently, households may show stronger brand and size loyalties but lower price sensitivity for food items in the online store than in the offline stores. Thus we have:

H7: Online-offline differences in brand loyalty, size loyalty and price sensitivity are greater for food products than for non-food products.

Degeratu et al (2000) divide a product's search characteristics into four groups: brand name, price, sensory and non-sensory characteristics. Sensory characteristics are those that can only be verified by senses, particularly by touch and smell, while non-sensory characteristics are those that can be easily expressed verbally. For example, the scent of perfumes and the texture of paper towels are sensory characteristics, whereas the fat content of margarine is a non-sensory characteristic. It is easy to uncover search attributes such as brand names and prices, both online and offline, but it is difficult, sometimes even impossible, to convey a product's sensory features in the online store. When sensory features are important factors in the purchase decision (sensory products) and when such features cannot be verified prior to purchase, households may rely on brand names, or buy the familiar brands. Alternatively, they may simply repeat the brands purchased on the previous occasions to reduce risk (Campbell and Goodstein 2001). Thus, consumers are likely to show stronger brand and size loyalty and lower price sensitivity in the 
online store than in the offline stores when buying sensory products than non-sensory products. We therefore hypothesize:

H8: Online-offline differences in brand loyalty, size loyalty and price sensitivity are greater for sensory products than for non-sensory products.

\section{DATA}

\section{The Grocery Retailer}

Our data come from one of the five leading grocery chains in Spain. This grocery chain has a prominent presence throughout Spain. It started online operations in 2001 and has been one of the most successful online grocers in Spain. The data are for one metro area, where the retailer has about 200 physical stores. The online store is the retailer's largest store by revenue. It partners with 17 of the chain's physical stores for grocery supply. After placing an order online, a household has two options: it can either go to one of these partner stores to pick up the order for no charge or have the basket delivered home with delivery charges ( $€ 4.5$ delivery fee for orders under $€ 90$, or free otherwise). An important feature of grocery stores in the metro area is that they do not always have parking lots, so consumers usually walk or take public transport to do grocery shopping. About $60 \%$ physical stores in this chain also provide home delivery service. The delivery charge for offline shopping is $€ 3.5$ for orders below $€ 90$ and free otherwise.

The retailer has a Hi-Lo chain-wide promotion policy. Price cuts apply to all stores in the chain, both online and offline. The retailer also practices zone pricing for offline stores (a practice that was subsequently abandoned). There are two offline price zones. Roughly, stores in the lowincome area belong to the low-price zone, and those in the high-income area belong to the highprice zone. Average prices across all categories in the high price zone are about $3 \%$ higher. When this retailer started the online business, it applied the prices in the high-price offline zone to the online store.

\section{Household Panel Data}

We obtained online household panel data on 2,733 households from this retailer. To be 
included in the panel, a household needs to have made at least one online purchase at the retailer's online store prior to the data collection period. So, all panel households are online shoppers, although some of them did not make any online trips during the data period. We observe all trips both to the online and offline stores in this chain during 12/2002-11/2003. For each trip, we observe the entire basket of both consumer packaged goods and perishables. For each item, we have prices, quantity bought, and a detailed description. We have detailed demographics for these households, including household size, numbers of children, adults and elders, and distance to the closest offline stores. As we want to compare the same households' shopping behavior across the online and offline channels, we focus on the 2,432 mixed shoppers that shop across both channels in the data period. The households on average made 43.3 shopping trips during the one-year period, of which $27.9 \%$ occurred to stores in the low-price offline zone, $55.5 \%$ to stores in the high-price offline zone, and $16.6 \%$ to the online store. When shopping offline, households primarily visit stores in the price zone where they reside. Interestingly, households residing in the low-price zone are more likely to shop online than those in the highprice zone, even though they have a cheaper option nearby and shopping online implies higher monetary costs to them. Households in the low-price zone made $18.89 \%$ shopping trips to the online store and spent $43.69 \%$ grocery expenditure online, while households in the high-price zone made $15.27 \%$ shopping trips to the online store and spent $37.90 \%$ grocery expenditure online (see Table 2). Thus, it does not seem that the online store only attracts households who primarily shop at the high-price zone, and there is no associated selection bias.

$<$ Table 2 about here>

\section{Choice of Categories}

We use three criteria to select the categories. (1) The category should have at least two brands and two sizes for households to choose from, or there would be no variation in brand choice or size choice. (2) There should be enough number of households buying the category both online and offline. This is to ensure the statistical power of the analysis. (3) There should be enough 
numbers of food and non-food categories, as well as sensory and non-sensory categories. This is to ensure the statistical power of the hypothesis tests. All together, we choose 93 categories, of which 66 are food products and 43 are sensory products. We summarize these categories in Table 3. For each category, we only use those households that made at least one online and one offline purchase in that category.

$<$ Table 3 about here>

A product category is defined as a sensory category when transparent or semi-transparent packaging allows shoppers to judge the real appearance of the product prior to purchase in a physical store. A product category is defined as non-sensory when opaque packaging makes it impossible for shoppers to examine its appearance either online or offline. We adopted this classification because it is easy to implement (we only need to check the characteristics of the category packages) and appropriate for grocery products where packaging plays an important role. We checked our sensory/ non-sensory classification using a convenience sample by mall intercept and found it provides an accurate representation of the sensory nature of the product categories considered.

\section{METHODOLOGY}

Our testing of the hypotheses consists of two steps. We first estimate a demand model of purchase incidence and brand choice to get coefficients on brand loyalty, size loyalty and price for the online and offline channels. Importantly, we use a household's store visits and purchases in both channels and estimate the online and offline coefficients jointly in the same demand model. We then compute elasticities for brand loyalty, size loyalty and price sensitivity. Next, we regress the online and offline elasticities on household and product characteristics to see whether there exist systematic differences across households and products.

\section{Model of Purchase Incidence and Brand Choice}

We follow the standard random utility approach for the demand model. We assume that on a given shopping trip, a household either chooses an alternative that yields the highest utility in a 
particular category, or chooses not to purchase in the category. The specification of the demand model is similar to Chu et al. (2008), but differs in that we assume a discrete distribution of observed household heterogeneity in brand and size loyalties and price sensitivity. This is to facilitate the hypothesis tests in the second step. A discrete specification is also more useful for the retailer's segmentation and targeting strategies. Further, due to the large number of categories involved, we do not account for unobserved household heterogeneity, but run analysis on a smaller subset of categories to check the robustness of our conclusions (see the subsection on robustness checks). On a shopping trip in week $t$, the indirect utility of household $h$ of Type $i$ (explained below) from choosing alternative $\omega$ of brand $b$ of size $z$ (in category $c$ ) from store $s$ is:

$$
\begin{aligned}
& U_{h(i) \omega s t}=\alpha_{b}+\alpha_{z}+D_{h} \gamma+ \\
& D_{h} B L_{h \omega t}\left(I_{s t}^{o n} \theta_{D}^{o n}+I_{s t}^{o f f} \theta_{D}^{\text {off }}\right)+D_{h} S L_{h \omega t}\left(I_{s t}^{o n} \lambda_{D}^{o n}+I_{s t}^{o f f} \lambda_{D}^{\text {off }}\right)+D_{h} P_{\omega s t}\left(I_{s t}^{o n} \beta_{D}^{o n}+I_{s t}^{\text {off }} \beta_{D}^{\text {off }}\right)+ \\
& \left\{\left(I_{s t}^{\text {on }} \theta_{i}^{\text {on }}+I_{s t}^{\text {off }} \theta_{i}^{\text {off }}\right) B L_{h \omega t}+\left(I_{s t}^{o n} \lambda_{i}^{\text {on }}+I_{s t}^{\text {off }} \lambda_{i}^{\text {off }}\right) S L_{h \omega t}+\left(I_{s t}^{o n} \beta_{i}^{o n}+I_{s t}^{\text {off }} \beta_{i}^{\text {off }}\right) P_{\omega s t}\right\} I_{h i}+\varepsilon_{h \omega s t}
\end{aligned}
$$

$\alpha_{b}$ is the intrinsic brand preference and $\alpha_{\mathrm{z}}$ the intrinsic size preference, $D_{h}$ includes family size, numbers of preschool children and elders, and distance to the closest offline store, and $\gamma$ is the effect of demographics on category purchase. $B L_{h \omega t}$ is brand loyalty, $I_{s t}^{o n}$ and $I_{s t}^{\text {off }}$ are online and offline indicators, $\theta_{D}^{o n}$ and $\theta_{D}^{o f f}$ are the effects of demographics on online and offline brand loyalties. $S L_{h a t}$ is size loyalty, and $\lambda_{D}^{o n}$ and $\lambda_{D}^{\text {off }}$ are the effects of demographics on online and offline size loyalties. $P_{\omega s t}$ is retail price, and $\beta_{D}^{o n}$ and $\beta_{D}^{o f f}$ are the effects of demographics on online and offline price sensitivities. $I_{h i}$ is household type indicator, and $\theta_{i}^{\text {on }}, \theta_{i}^{\text {off }} \lambda_{i}^{\text {on }}, \lambda_{i}^{\text {off }}, \beta_{i}^{\text {on }}$ and $\beta_{i}^{\text {off }}$ are respectively online and offline parameters for brand loyalty, size loyalty and price sensitivity for households of Type $i$. Ehost is household $h$ 's idiosyncratic utility.

We define brand and size loyalties as exponentially weighted averages of past purchases as in Guadagni and Little (1983). Guadagni and Little estimated the smoothing constant as .875 for brand loyalty and .812 for size loyalty. However, Ortmeyer (1985) and Gupta (1988) 
demonstrated their model's fit and parameter estimates are very robust to small changes $(+/-.1)$ in the smoothing constant. Hence, instead of estimating, we pre-specify the constants as .8 as in Gupta (1988). A sensitivity analysis with smoothing constants as .7 and .9 for four categories corroborates Ortmeyer's and Gupta's findings. Brand and size loyalties are initialized as suggested by Guadagni and Little (1983). For example, for the $1^{\text {st }}$ purchase occasion of household $h, B L_{h \omega t}$ is set to the smoothing constant value of .8 if the brand (size) of alternative $\omega$ was bought, otherwise $.2 /$ (number of brands (sizes) -1 ). This step ensures that the sum of loyalties across brand names (sizes) always equals 1 for a household.

$$
\begin{aligned}
& B L_{h \omega t}=0.8 B L_{h \omega t-1}+0.2 \begin{cases}1 & \begin{array}{l}
\text { if Household } h \text { bought the brand of alternative } \omega \\
\text { at purchase occasion } t-1
\end{array} \\
0 & \text { otherwise }\end{cases} \\
& S L_{h \omega t}=0.8 S L_{h \omega t-1}+0.2 \begin{cases}1 & \text { if Household } h \text { bought the size of alternative } \omega \\
\text { at purchase occasion } t-1\end{cases} \\
& 0 \text { otherwise }
\end{aligned}
$$

We use two ways to capture household heterogeneity. (1) We allow demographics to affect the overall category purchase probability $(\gamma)$ and online and offline brand loyalties ( $\theta_{D}^{\text {on }}$ and $\theta_{D}^{\text {off }}$ ), size loyalties ( $\lambda_{D}^{o n}$ and $\lambda_{D}^{o f f}$ ), and price sensitivities ( $\beta_{D}^{o n}$ and $\beta_{D}^{o f f}$ ). (2) We group households into three types - "light online shoppers", "moderate online shoppers" and "heavy online shoppers", based on the proportions of their total grocery expenditure spent at the online store, and estimate type-specific loyalty and price coefficients. "Light online shoppers" $(44.76 \%)$ are households with online expenditure $<25 \%$, "moderate online shoppers" $(28.85 \%)$ are households with online expenditure between $25 \%$ and $60 \%$, and "heavy online shoppers" $(26.40 \%)$ are households with online expenditure $>60 \%$ of total grocery expenditures recorded at that chain. The no-purchase utility is:

$$
U_{h 0 s t}=X_{h t}\left(I_{s t}^{o n} \theta_{o n}+I_{s t}^{o f f} \theta_{o f f}\right)+\varepsilon_{h 0 s t}=V_{h 0 s t}+\varepsilon_{h 0 s t}
$$


Where, $X_{h t}$ includes (1) weather dummy, (2) weekday dummy, (3) purchase quantity on the last trip divided by household size, and (4) a lagged purchase indicator that takes the value 1 if the household purchased the category on the most recent trip (to capture inventory effects but mitigating the endogeneity problem associated with using inventory or time since last purchase). Assuming $\varepsilon_{\text {host }}$ follows an extreme value distribution yields the logit probability of item choice:

$$
S_{h(i) \omega s t}=\frac{\exp \left\{\alpha_{b}+\alpha_{z}+D_{h} \gamma+V_{D \omega s t}+V_{h \omega s t}\right\}}{\exp \left(V_{h 0 s t}\right)+\sum_{\omega^{\prime}=1}^{\Omega} \exp \left\{\alpha_{b}+\alpha_{z}+D_{h} \gamma+V_{D \omega^{\prime} s t}+V_{h \omega^{\prime} s t}\right\}}
$$

Where $V_{D \omega s t} \equiv D_{h} B L_{h \omega t}\left(I_{s t}^{o n} \theta_{D}^{o n}+I_{s t}^{o f f} \theta_{D}^{o f f}\right)+D_{h} S L_{h \omega t}\left(I_{s t}^{o n} \lambda_{D}^{o n}+I_{s t}^{o f f} \lambda_{D}^{o f f}\right)+D_{h} P_{\omega s t}\left(I_{s t}^{o n} \beta_{D}^{o n}+I_{s t}^{o f f} \beta_{D}^{o f f}\right)$ and $V_{h \omega s t} \equiv\left\{\left(I_{s t}^{o n} \theta_{i}^{o n}+I_{s t}^{o f f} \theta_{i}^{\text {off }}\right) B L_{h \omega t}+\left(I_{s t}^{o n} \lambda_{i}^{o n}+I_{s t}^{\text {off }} \lambda_{i}^{\text {off }}\right) S L_{h \omega t}+\left(I_{s t}^{o n} \beta_{i}^{o n}+I_{s t}^{\text {off }} \beta_{i}^{\text {off }}\right) P_{\omega s t}\right\} I_{h i}$ and $\Omega$ is the set of alternatives available to households.

Methods for Hypothesis Testing

After obtaining the online and offline coefficients for brand loyalty, size loyalty and price sensitivity, we compute elasticities for brand loyalty, size loyalty and price elasticity (we recognize that it is somewhat unusual to compute "loyalty elasticities" but do this largely to facilitate comparisons across households and categories). We then use regression and t-tests to test the various hypotheses. Note that since the dependent variables here are estimated quantities, we need to account for the sampling error associated with their estimation in this stage of the analysis. We therefore use the estimated covariance matrix computed from the estimates of the logit model in a generalized least-squares regression ${ }^{1}$. Specifically, we do the following:

(1) We compute the ratios of online/offline elasticities for brand loyalty, size loyalty and price elasticities and test whether the ratios are significantly different from 1 . This is to check whether households are more brand loyal, more size loyal and less price sensitive in the online channel than in the offline channel.

\footnotetext{
${ }^{1}$ In addition to using generalized least squares, we also tried a bootstrapping approach to adjust for the standard errors. This does not change our conclusions.
} 
(2) We stack together the online (offline) brand loyalty, size loyalty or price sensitivity of all three household types and regress them on category dummies, household type dummies and household demographics. This is to check the within-channel relationships in brand loyalty, size loyalty and price sensitivity across households of different online shopping frequency. Take price elasticities as an example. We have:

$$
\begin{aligned}
& \varepsilon_{c, i}^{o n}=\kappa_{c, \text { on }} I_{c}+\kappa_{\text {light }, \text { on }} I_{\text {light }}+\kappa_{\text {moderate on }} I_{\text {moderate }}+\kappa_{D, \text { on }} D_{c, i}+e_{c, i}^{o n} \\
& \varepsilon_{c, i}^{\text {off }}=\kappa_{c, \text { off }} I_{c}+\kappa_{\text {light }, \text { off }} I_{\text {light }}+\kappa_{\text {moderate, off }} I_{\text {moderate }}+\kappa_{D, \text { off }} D_{c, i}+e_{c, i}^{\text {off }}
\end{aligned}
$$

Where $\varepsilon_{c, i}^{o n}\left(\varepsilon_{c, i}^{o f f}\right)$ is household Type $i$ 's online (offline) price elasticity for category $c, I_{\mathrm{c}}$ is category indicator, and $I_{\text {light }}$ and $I_{\text {moderate }}$ are indicators for light and moderate online shoppers. $D_{c, i}$ is the mean demographics of household Type $i$ that makes purchases in category $c$, including number of preschool children, number of elders, family size and distance to the closest physical stores. We include demographics in this regression because the elasticities may reflect the effects of demographics (see equation (1)). We are interested in coefficients $\kappa_{\text {light,on }}\left(\kappa_{\text {light,off }}\right)$ and $\kappa_{\text {moderate, on }}\left(\kappa_{\text {moderate, off }}\right)$. If $\kappa_{\text {light,on }}>0$, it means light online shoppers are less price sensitive in the online store than heavy online shoppers (whose coefficient is normalized to 0 ). If $\kappa_{\text {moderate,on }}>0$, it means moderate online shoppers are less price sensitive in the online store than heavy online shoppers. If $\kappa_{\text {light,on }}>\kappa_{\text {moderate, on }}>0$, it means light online shoppers are the least and heavy online shoppers are the most price sensitive in the online store.

(3) We stack together online and offline brand loyalty, size loyalty and price elasticities for all three household types and regress them on category dummies, the interactions between online indicator with indicators for food, sensory, light online shoppers and moderate online shoppers, and household demographics. This is to check whether household and product characteristics moderate online and offline differences in brand loyalty, size loyalty and price sensitivity. Take price elasticities as an example. We have: 


$$
\begin{aligned}
\varepsilon_{c, i}=\rho_{c} I_{c} & +\rho_{\text {food }} \text { Food }_{c} * I_{\text {on }}+\rho_{\text {sensory }} \text { Sensory }_{c} * I_{\text {on }} \\
& +\rho_{\text {light on }} I_{\text {light }} * I_{\text {on }}+\rho_{\text {moderate }, \text { on }} I_{\text {moderate }} * I_{\text {on }}+\rho_{D} D_{c, i}+e_{c, i}
\end{aligned}
$$

Where $\varepsilon_{c, i} \equiv\left\{\varepsilon_{c, i}^{o n}, \varepsilon_{c, i}^{o f f}\right\}$ is the vector of household Type $i$ 's online and offline price elasticities in category $c$, and $I_{\mathrm{on}}$ is online indicator. $\rho_{\text {food }}$ is online-offline difference in price sensitivity for food products (the difference for non-food products is normalized to 0 ). $\rho_{\text {sensory }}$ is online-offline difference in price sensitivity for sensory products (the difference for non-sensory products is normalized to 0$)$. $\rho_{\text {light,on }}$ and $\rho_{\text {moderate, on }}$ are respectively online-offline differences in price sensitivity for light online shoppers and moderate online shoppers (the difference for heavy online shoppers is normalized to 0 ). If $\rho_{\text {food }}>0$, it means online-offline price elasticity difference for food products is greater than for non-food products. If $\rho_{\text {sensory }}>0$, it means online-offline price elasticity difference for sensory products is greater than for non-sensory products. If $\rho_{\text {light, on }}>$ $\rho_{\text {moderate, on }}>0$, it means online-offline difference in price sensitivity is largest for light online shoppers and smallest for heavy online shoppers. Note the logit model coefficients are estimated up to a scale factor, so elasticities of different models (different categories here) are not directly comparable if the scale effect is not controlled for (Swait and Louviere 1993). This is resolved in our model by including category fixed effects ${ }^{2}$.

\section{Robustness Checks}

We conducted a series of robustness checks on model specification, classification of household types and self selection bias, and found our conclusions remain the same.

Potential endogeneity bias due to omitted variables. Our model does not account for retailer promotion efforts such as features and displays due to data unavailability. If these variables are

\footnotetext{
${ }^{2}$ Elasticity estimates from the same logit model are comparable because they have the same logit scale factor. Elasticity estimates from different logit models are not comparable because they have different scale factors. Since we model each category separately, each category has its own logit model and scale factor. Thus, elasticities for light, moderate and heavy online shoppers for the same category are comparable, but elasticities for different categories are not comparable because they come from different logit models and have different scale factors. When we include category fixed effects, the common scale factor for each category will be absorbed by category fixed effects, making elasticities from different models comparable.
} 
correlated with the included price variable, the estimated price effects can suffer from an endogeneity bias. Chu et al (2008) show that accounting for price endogeneity does not change the directional relationship between online and offline price sensitivity. We tried to address price endogeneity using the same approach as in Chu et al (2008) with the four categories in Table 4 and found that our conclusions remain unchanged.

Unobserved household heterogeneity. One caveat of our study is that we do not account for unobserved household heterogeneity due to the large number of categories involved. To assess how this will affect our findings, we estimated a random coefficients logit model for 33 categories, assuming normal distributions for brand loyalty, size loyalty and price sensitivity coefficients for all three household types and re-ran the hypothesis tests. The results are in the Appendix. We obtain qualitatively similar results, though the significance of some coefficients is compromised due to a smaller number of categories.

The possibility of self-selection bias. The households reside either in the high-price zone or in the low-price zone, while the prices in the online store are the same as in the high-price zone. In the data section, we showed that the online store does not only attract households in the highprice zone. Actually, it is slightly more attractive to households in the low-price zone. To further check whether there exists a self-selection bias, we divide households into three groups by their offline shopping behavior - those who only shop in the high-price zone, those who only shop in the low-price zone and those who shop across both price zones, and estimate the models separately for each group of households with the four categories in Table 4. We obtained similar results for all three groups of households, though the significance of the coefficient estimates is somewhat reduced due to a smaller sample in each model.

Continuous versus discrete operationalization of household types for online grocery expenditure. Instead of using a continuous measure and interacting it with brand loyalty, size loyalty and price in the demand model, we bin households into three types according to their percentages of online grocery expenditure in the total grocery expenditure incurred in the chain. 
This is because findings based on the discrete operationalization can be easily applied by the retailer for market segmentation and targeting purposes. We compared the stability of a household's online expenditure over time, and find it is very stable and thus can be treated as a household characteristic. This is consistent with the finding in Chintagunta, Chu and Cebollada (2010) that online shopping is more regular both in terms of trip interval and basket size.

\section{RESULTS}

In this section, we first report demand parameter estimates and loyalty and price elasticities for 4 categories - one sensory food product (packed tomatoes), one non-sensory food product (flour), one non-sensory non-food product (liquid laundry detergent), and one non-food sensory product (paper towel). Results of other categories are available from the authors. We then report the results of the hypothesis tests.

\section{Demand Parameter Estimates}

In Table 4, we report key demand parameter estimates and in Table 5, we report online and offline loyalty elasticities and price elasticities for light, moderate and heavy online shoppers for packed tomatoes, flour, liquid laundry detergent and paper towels. Across all four categories, irrespective of online shopping frequency, households demonstrate strong brand and size loyalties. Consistent with the literature, for all three types of households, online brand loyalty is greater than offline brand loyalty, online size loyalty is greater than offline size loyalty, and online price sensitivity is smaller than offline price sensitivity. The differences are significant at the $99 \%$ level.

<Table 4 about here>

The majority of the coefficients of the interactions between demographics and brand loyalty, demographics and size loyalty, and demographics and price are significant, implying that demographics play an important role in determining online and offline brand loyalty, size loyalty, and price sensitivity. But the signs of the interaction coefficients are not the same across categories.

$<$ Table 5 about here> 
In Table 6, we summarize the directional relationships in online and offline brand loyalty, size loyalty and price elasticities for the three types of households. For light online shoppers, 89\% categories have larger online brand loyalty and size loyalty elasticities than offline, and all categories have smaller (in magnitude) online price elasticity. For moderate online shoppers, $85 \%$ have larger online brand loyalty elasticity, $88 \%$ have larger online size loyalty elasticity, and $90 \%$ have larger online price elasticity. For heavy online shoppers, the figures are respectively $86 \%$, $88 \%$ and $70 \%$. From the elasticities, we can see that households are more brand loyal, more size loyal but less price sensitive in the online channel than in the offline channel.

$<$ Table 6 about here $>$

In Table 7, we show how the same households' online and offline brand loyalty, size loyalty and price elasticities are correlated. For all three household types, online brand loyalty is positively correlated with offline brand loyalty, online size loyalty is positively correlated with offline size loyalty, and online price sensitivity is positively correlated with offline price sensitivity, indicating some consistency in a household's shopping behavior across the two channels. Brand loyalty, size loyalty and price sensitivity are also positively correlated, but the correlation coefficients are either small, or not significant.

\section{$<$ Table 7 about here>}

\section{Comparison of Online and Offline Brand Loyalties, Size Loyalties and Price Sensitivities}

We compute the ratios of online/offline brand loyalty, size loyalty and price elasticities, and test whether the ratios are significantly different from 1, respectively for all households together and for each type of households (Table 8). We find that, consistent with the literature, all types of households exhibit stronger brand loyalty and size loyalty in the online store than in the offline stores, but lower price sensitivity in the online store than in the offline stores.

<Table 8 about here>

Comparison of within-channel Brand Loyalty, Size Loyalty and Price Sensitivity by Household

\section{Characteristics}


To test whether online and offline behaviors differ by online shopping frequency, we regress online and offline brand loyalties, size loyalties and price elasticities respectively on category dummies, household type dummies and household demographics (Equation 5). The results are in Table 9. Light online shoppers are more brand loyal than heavy online shoppers both in the online and offline channels. There is no significant difference in brand loyalty between light and moderate online shoppers, as well as between moderate and heavy online shoppers. This supports H1. Similarly, light online shoppers are more size loyal than heavy online shoppers both in the online and offline channels. There is no significant difference between light and moderate and between moderate and heavy online shoppers in size loyalty. This supports H2.

<Table 9 about here>

In the online channel, light online shoppers are significantly less price sensitive than moderate and heavy online shoppers, and moderate online shoppers are slightly less price sensitive than heavy online shoppers. This supports H3a and H3b. In the offline channel, light online shoppers are less price sensitive than moderate online shoppers, but more price sensitive than heavy online shoppers, and moderate online shoppers are also more price sensitive than heavy online shoppers. In other words, the moderate online shoppers show the highest price sensitivity and the heavy online shoppers show the lowest price sensitivity in the offline channel. This supports $\mathrm{H} 3 \mathrm{c}$ and $\mathrm{H} 3 \mathrm{~d}$.

In sum, we find support for $\mathrm{H} 1, \mathrm{H} 2$ and $\mathrm{H} 3 \mathrm{a}-\mathrm{H} 3 \mathrm{~d}$, confirming that in the online store light online shoppers are more brand loyal and less price sensitive than heavy online shoppers, while in offline stores they are more price sensitive than heavy online shoppers, but less price sensitive than moderate online shoppers.

Online-offline Differences in Brand Loyalty, Size Loyalty and Price Sensitivity by Household and

\section{Product Characteristics}

To test how online-offline behavioral differences are affected by household and product characteristics, we stack online and offline brand loyalties, size loyalties and price elasticities and 
regress them on the interactions between online indicator and dummies for household and product characteristics and demographics (Equation 6). The results are in Table 10. For brand loyalty, the online-offline difference is largest for light online shoppers and smallest for heavy online shoppers. This supports H4. For size loyalty, the online-offline difference is larger for light and moderate online shoppers than for heavy online shoppers, and there is no significant difference between light and moderate online shoppers. This supports H5. For price sensitivity, the difference is largest for light online shoppers and second largest for moderate online shoppers, supporting H6.

\section{$<$ Table 10 about here>}

The online-offline difference in brand loyalty is significantly larger for food products than for non-food products. The online-offline difference in size loyalty is also significantly larger for food products than for non-food items. The online-offline difference in price sensitivity is significantly larger for food products than for non-food products. This supports H7. The onlineoffline difference in brand loyalty is significantly larger for sensory products than for non-sensory products, the difference in size loyalty is directionally larger for sensory products than for nonsensory products, and the difference in price sensitivity is significantly larger for sensory products. This supports H8.

To summarize, we find empirical support for all our hypotheses. We find that households are more brand loyal, more size loyal and less price sensitive in the online channel than in the offline channel. Households' online shopping frequency affects brand loyalty, size loyalty and price sensitivity. In the online channel, light online shoppers are more brand loyal, more size loyal but less price sensitive than heavy online shoppers, while in the offline channel, heavy online shoppers are the least and moderate online shoppers are the most price sensitive. The onlineoffline differences in brand loyalty, size loyalty and price sensitivity are largest for light online shoppers and smallest for heavy online shoppers, larger for food products than for non-food products, and larger for sensory products than for non-sensory products. 
Our findings have important implications for Internet retail practice as shown in Table 11. One implication concerns retailer pricing policy. The findings suggest specific pricing actions for the retailer in question - a well-established grocery chain in Spain. This retailer used to practice zone pricing in the offline stores. The offline stores were partitioned into a high-price zone and a low-price zone. When this retailer started the online arm, it did not change its pricing policy for the offline stores. Nor did it develop online prices different from its offline zone prices. Rather, it decided to use the prices in the high-price offline zone for the online store (Now the retailer practices uniform pricing across both online and offline stores). We find that regardless of online shopping frequency, the same households exhibit lower price sensitivity in the online store than in the offline stores. This finding suggests that the retailer can be better off if it can fine tune its pricing policies for the two channels so that the online prices can be better matched to household online price sensitivity. The retailer can estimate average online and offline price sensitivities across households shopping in each channel and set online and offline prices accordingly. The lower online price sensitivities mean the retailer can charge price premiums in the online store.

$<$ Table 11 about here>

A second implication concerns the differential price sensitivities across households of different online shopping frequency and the possibility of market segmentation and targeting. Given the popularity of the loyalty card program, it is not difficult for the retailer to find out which households are heavy online shoppers and which households are light online shoppers. Given that light online shoppers are least price sensitive and heavy online shoppers are most price sensitive in the online store, the retailer may consider using different promotional policies such as targeted coupon drops and email promotions to different types of households. For example, they can send deeper online promotion coupons to heavy online shoppers, and send deeper offline promotion coupons to moderate online shoppers.

A third implication is about different product offerings in the online and offline channels. 
Given that online and offline differences in brand loyalty and price sensitivity are larger for food products than for non-food products and larger for sensory products than for non-sensory products, the retailer may consider offering different products in different channels. Instead of offering the same products across the two channels, it may want to offer more non-food products and non-sensory products in the online store, and offer more food products and more sensory products in the offline stores. Although this implication is intuitive, our results provide a strong empirical basis for such a recommendation.

The finding that product characteristics influence consumer behavior in the online store differently from the offline stores should help manufacturers and retailers tailor their marketing strategies to different channels. For example, the larger online-offline difference in price sensitivity for sensory products than for non-sensory products implies that the retailer can extract higher margins for sensory products in the online store than in the offline stores. It can encourage consumers to buy sensory products in the online store, or even set higher prices for sensory products in the online store. This is to extract more consumer surplus from those households that do buy sensory products in the online store. In terms of sales volume, the retailer may have lower sales of sensory products in the online store, but in terms of unit margin, the retailer can get a higher margin from selling sensory products in the online store.

Our research confirms the complementary nature of the online store to offline stores. For many households, the online store is an extension of the physical stores that has more flexible shopping hours and alleviates the burden of grocery shopping. These households are least price sensitive in the online store but are most price sensitive in the offline stores. The retailer should promote its online store to its customers who have not adopted its online store. This is because when these households adopt the online store, they will likely use the Internet as a supplementary channel and be less price sensitive in that channel, allowing the retailer to charge a price premium.

Our paper has several limitations that should be addressed by future research. First, our demand model does not account for retailer promotion efforts such as features and displays due to 
data unavailability. Even though we show that this omission will not likely affect our conclusions, including these variables will enhance the managerial value of the findings. Second, there are additional product characteristics such as competitive intensity and deal elasticity that may moderate a household's brand and size loyalties and price sensitivity. Again, due to lack of data, we do not address them in this paper. Third, we model a household's purchase incidence and brand choice decisions conditional on its channel choice decision. We recognize the limitation of treating channel choice as exogenous, but a single category may not be adequate to drive a household's channel choice decisions (Chintagunta et al 2010, Chintagunta and Chu 2010). Formulating and estimating a store/channel choice model with as many categories as we have would be a challenging task. We leave it to future research to model channel choice, purchase incidence and brand choice simultaneously. Fourth, we compare online and offline purchase behaviors related to grocery products, which are not the typical products sold online. Future studies can compare the results with those obtained with non-grocery products such as books, CDs and PCs.

In conclusion, we analyzed households' channel-specific brand loyalty, size loyalty and price sensitivity in 93 categories of food, non-food, sensory and non-sensory grocery products and test whether these behaviors differ by household characteristics (online shopping frequency) and product characteristics (food versus non-food, sensory versus non-sensory). Consistent with the literature, we find the same households are more brand loyal, more size loyal and less price sensitive in the online store than in the offline stores. Importantly, our results show that the online and offline behavioral differences are moderated by household and product characteristics.

Given the potential of the Internet and its increasing importance throughout the world, many retailers now have online operations. Our study reveals that consumer behavior in the online store does not simply mimic that in the conventional channel. Firms need to tailor their marketing strategies so as to better cater to consumer's online behavior. 


\section{REFERENCES}

Andrews, Rick and Imran Currim (2004), "Behavioral Differences between Consumers Attracted

to Shopping Online vs. Traditional Supermarkets: Implications for Enterprise Design \& Marketing Strategy," International J. of Marketing \& Advertising, 1, 1, 38-61.

Bakos, Yannis (1997), "Reducing Buyer Search Costs: Implications for Electronic Marketplaces,” Management Science, 43, 12, 1676-1692.

Beatty, Sharon, Pamela Homer and Lynn R. Kahle (1988), "The Involvement - Commitment

Model: Theory and Implications", Journal of Business Research, 16, 2, 149-167.

Brynjolfsson, Erik and Michael D. Smith (2000), "Frictionless Commerce? A Comparison of Internet and Conventional Retailers," Management Science, 46, 4, 563-585.

Campbell, Margaret C. and Ronald C. Goodstein (2001), “The Moderating Effect of Perceived Risk on Consumers' Evaluations of Product Incongruity: Preference for the Norm”, Journal of Consumer Research, 28, 3, 439-449.

Cheema, Amar and Purushottam Papatla (2009), "Relative Importance of Online Versus Offline Information for Internet Purchases: Product Category and Internet Experience Effects", Journal of Business Research, forthcoming.

Chintagunta, Pradeep K. and Junhong Chu (2010), "Category Selection and Store Choice Modeling", working paper, NUS Business School.

Chintagunta, Pradeep K., Junhong Chu and Javier Cebollada (2010), "What Drives Household Choice of Online and Offline Grocery Channels?” working paper, NUS Business School.

Chu, Junhong, Pradeep K. Chintagunta and Javier Cebollada (2008), “A Comparison of withinhousehold Price Sensitivity across Online and Offline Channels," Marketing Science, 27, 2, 283299.

Danaher, Peter J., Isaac W. Wilson and Robert A. Davis (2003), “A Comparison of Online and Offline Consumer Brand Loyalty," Marketing Science, 22, 4, 461-476. 
Degeratu, Alexandru M., Arvind Rangaswamy and Jianan Wu (2000), "Consumer Choice Behavior in Online and Traditional Supermarkets: The Effects of Brand Name, Price, and Other Search Attributes," International Journal of Research in Marketing, 17, 1, 55-78.

Grewal, Dhruv, Gopalkrishnan R. Iyer and Michael Levy (2004), “Internet Retailing: Enablers, Limiters and Market Consequences,” Journal of Business Research, 57, 7, 703-713.

Guadagni, Peter M. and John D.C. Little (1983), “A Logit Model of Brand Choice Calibrated on Scanner Data," Marketing Science, 2, 3, 203-238.

Gupta, Sunil (1988), "Impact of Sales Promotions as When, What, and How Much to Buy," Journal of Marketing Research, 25, 4, 342-355.

Kacen, Jacqueline J., James D. Hess and Wei-yu Kevin Chiang (2002), "Bricks or Clicks? Consumer Attitudes toward Traditional Stores and Online Stores," working paper, UIUC.

Lal, Rajiv and Miklos Sarvary (1999), "When and How is the Internet likely to Decrease Price Competition?" Marketing Science, 18, 4, 485-503.

Lynch, John G. and Dan Ariely (2000), "Wine Online: Search Costs Affect Competition on Price, Quality and Distribution," Marketing Science, 19, 1, 83-103.

Morrison, Donald G. (1979), "Purchase Intentions and Purchase Behavior", Journal of Marketing, $43,2,65-74$.

Ortmeyer, Gwen K. (1985), “A Model of Consumer Response to Promotions,” unpublished dissertation, Stanford University.

Park, C. Whan, Easwar S. Iyer and Daniel C. Smith (1989), “The Effects of Situational Factors on In-store Grocery Shopping Behavior: the Role of Store Environment and Time Available for Shopping”, Journal of Consumer Research, 15, 4, 422-433.

Png, Ivan P.L. and David Reitman (1995), "Why Are Some Products Branded and Others Not?" Journal of Law and Economics, 38, 1, 207-224.

Pozzi, Andrea (2008), “Shopping Cost an-d Brand Exploration in Online Grocery," working paper, Department of Economics, Stanford University. 
Putrevu, Sanjay and Brian T. Ratchford (1997), "A Model of Search Behavior with an Application to Grocery Shopping," Journal of Retailing, 73, 4, 463-486.

Sehgal, Vikram (2010a), “Forrester Research Online Retail Forecast, 12/09 (US)”, (accessed March 10, 2010), www.forrester.com.

— (2010b), "Forrester Research Online Retail Forecast, 1/10 (Western Europe)”, (accessed

March 10, 2010), www.forrester.com.

Shankar, Venkatesh, A. Rangaswamy \& M. Pusateri (2001), “The Online Medium and Customer Price Sensitivity",

http://www.venkyshankar.com/home/ViewAbstract.cfm?AbsIndex=44\&ReturnPage=default, (accesses February 24, 2010)

Shankar, Venkatesh, Amy Smith and Arvind Rangaswamy (2003), "Customer Satisfaction and Loyalty in Online and Offline Environments," International Journal of Research in Marketing, $20,2,153-75$.

Swait, Joffre and Jordan Louviere (1993), "The Role of the Scale Parameter in the Estimation and Comparison of Multinomial Logit Models," Journal of Marketing Research, 30, August, 305-314. Taylor, Mark B (1984), "Ego Involvement and Brand Commitment: Not Necessarily the Same", Journal of Consumer Marketing, 1, 2, 75-79.

The Daily Telegraph (2009), "Online shopping 'soars in popularity as Brits avoid supermarket hassle"', April 20

Tsiros, Michael and Carrie M. Heilman (2005), "The Effect of Expiration Dates and Perceived Risk on Purchasing Behavior in Grocery Store Perishable Categories," Journal of Marketing, 69, April, 114-129.

Warrington, Patti and Soyeon Shim (2000), “An empirical investigation of the relationship between product involvement and brand commitment," Psychology \& Marketing, 17, 9, 761-782. Wernerfelt, Birger (1988), “Umbrella Branding as a Signal of New Product Quality: An Example of Signaling by Posting a Bond,” Rand Journal of Economics, 19, 3, 458-466. 
Table 1

Selected Studies on Brand Loyalty, Size Loyalty and Price Sensitivity across Online and Offline Channels

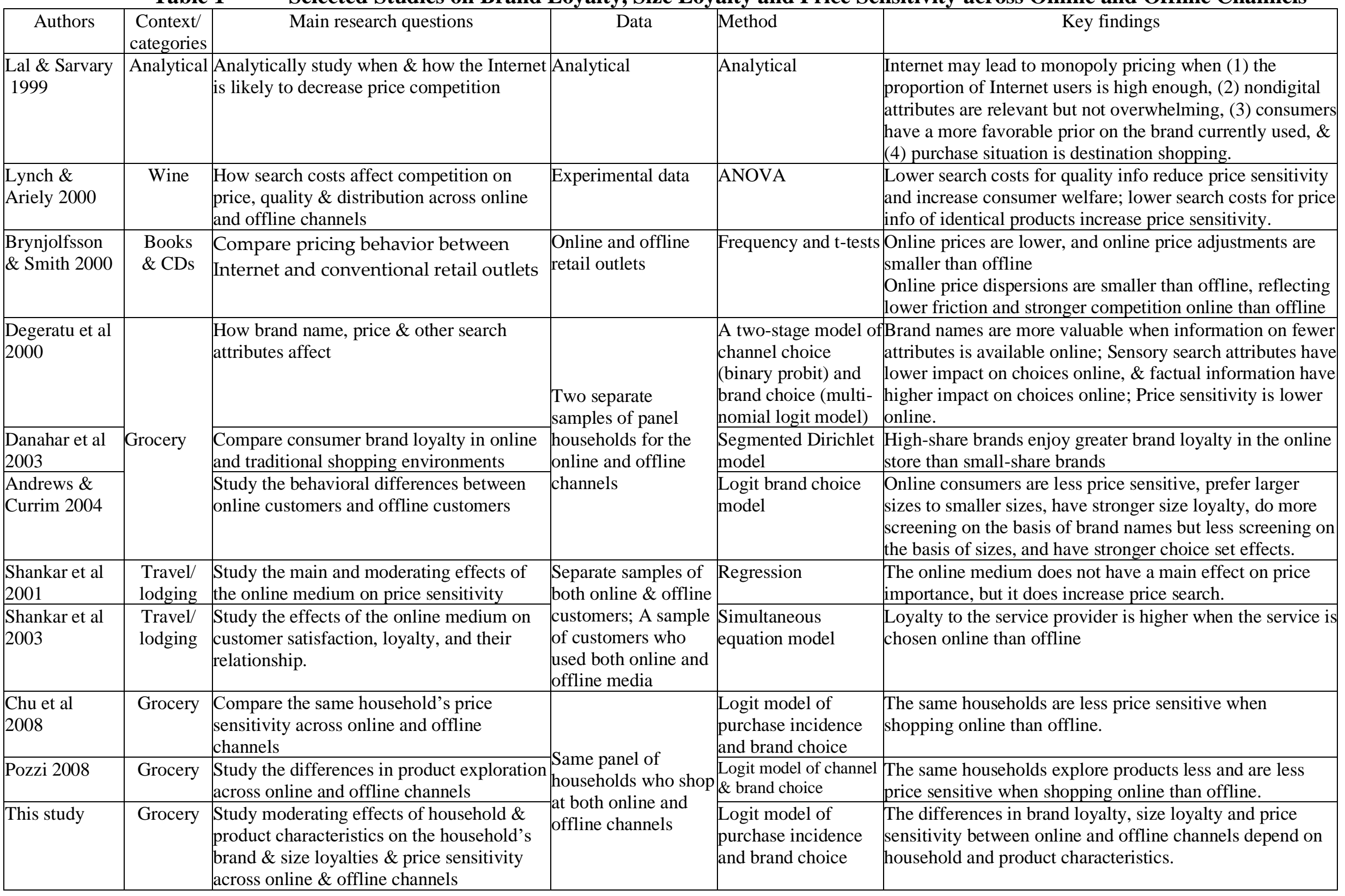


Table 2 Distribution of Shopping Trips and Grocery Expenditure by Price Zone and Channel

\begin{tabular}{|c|c|c|c|c|c|c|c|c|c|}
\hline & \multicolumn{3}{|c|}{$\%$ trips to stores in } & \multicolumn{3}{|c|}{$\%$ grocery spending in } & \multicolumn{3}{|c|}{ Per capita basket size } \\
\hline & $\begin{array}{l}\text { Low- High- } \\
\text { price price } \\
\text { zone zone } \\
\end{array}$ & \multicolumn{2}{|c|}{ online total } & \multicolumn{3}{|c|}{$\begin{array}{l}\text { Low- High- online Tot } \\
\text { price price } \\
\text { zone zone }\end{array}$} & \multicolumn{3}{|c|}{ 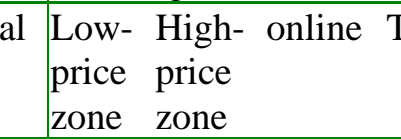 } \\
\hline \multirow{2}{*}{$\begin{array}{l}\text { Households in low-price zone } \\
\text { Households in high-price zone }\end{array}$} & 66.4814 .63 & 18.89 & .89100 & 42.1714 .1 & 443.69 & 100 & \multicolumn{3}{|c|}{$10.64 \quad 16.21 \quad 38.81$} \\
\hline & 5.4879 .25 & 15.27 & $.27 \quad 100$ & \multicolumn{2}{|c|}{3.8261 .25} & $.93 \quad 10$ & \multicolumn{3}{|c|}{$\begin{array}{lll}11.57 & 12.82 & 37.95\end{array}$} \\
\hline Total & 27.8555 .55 & & .60100 & 16.7845 & 5.3237. & .90 & 10.1 & 113.69 & $\begin{array}{ll}9 & 38.31\end{array}$ \\
\hline & Table 3 & & Summary & Statistics o & of the 93 & Categor & ries & & \\
\hline Category & \# of & & \# of Foo & od Sensory & $y \quad \#$ of & $\# \operatorname{tr}$ & rips & \# purc & chases \\
\hline & Items bran & & sizes & & $\mathrm{HH}$ & Online & Offline & Online & Offline \\
\hline Aluminum & 8 & 2 & 5 & 0 & 211 & 1,838 & 7,202 & 724 & 1,430 \\
\hline Asparagus & 22 & 7 & 11 & 1 & 363 & 2,226 & 13,660 & 948 & 1,431 \\
\hline Beer & 33 & 18 & 5 & 1 & 1173 & 8,246 & 44,922 & 5,829 & 9,644 \\
\hline Bleach & 28 & 7 & 6 & 0 & 930 & 6,357 & 36,711 & 3,748 & 4,765 \\
\hline Body wash & 34 & 20 & 6 & 0 & 806 & 5,692 & 29,463 & 2,551 & 2,871 \\
\hline Brandy & 5 & 5 & 2 & 1 & 117 & 942 & 4,332 & 369 & 630 \\
\hline Broth powder & 15 & 5 & 8 & 1 & 203 & 1,559 & 6,948 & 471 & 572 \\
\hline Butter & 18 & 7 & 3 & 1 & 676 & 4,799 & 24,348 & 2,083 & 3,241 \\
\hline Cereal & 53 & 12 & 5 & 1 & $0 \quad 1,026$ & 9,870 & 41,020 & 7,162 & 12,007 \\
\hline Packed cheese & 17 & 10 & 7 & 1 & 211 & 1,838 & 7,202 & 724 & 1,430 \\
\hline Liquid cleaner & 43 & 19 & 6 & 0 & $0 \quad 1,054$ & 8,377 & 41,028 & 4,763 & 5,722 \\
\hline Cleaning towel & 15 & 7 & 5 & 0 & 382 & 2,879 & 13,396 & 847 & 938 \\
\hline Cocoa spread & 17 & 8 & 10 & 1 & 792 & 6,161 & 29,211 & 3,157 & 4,092 \\
\hline Coffee & 50 & 6 & 8 & 1 & $0 \quad 1,273$ & 9,442 & 49,471 & 6,087 & 9,365 \\
\hline Conditioner & 11 & 6 & 4 & 0 & 147 & 1,010 & 4,420 & 354 & 428 \\
\hline Cream & 15 & 8 & 4 & 1 & 633 & 4,605 & 23,324 & 2,198 & 3,524 \\
\hline Dairy dessert & 40 & 7 & 15 & 1 & 855 & 8,831 & 34,915 & 6,259 & 12,961 \\
\hline Deodorant & 33 & 15 & 5 & 0 & 522 & 3,922 & 19,786 & 1,668 & 1,746 \\
\hline Dessert powder & 6 & 2 & 4 & 1 & 97 & 673 & 3,724 & 206 & 280 \\
\hline Liquid detergent & 26 & 18 & 9 & 0 & 887 & 6,271 & 35,436 & 3,902 & 4,926 \\
\hline Powder detergent & 28 & 27 & 21 & 0 & 678 & 4,384 & 26,379 & 2,577 & 3,293 \\
\hline Diaper & 30 & 13 & 22 & 0 & 632 & 6,031 & 24,954 & 4,041 & 6,019 \\
\hline Liquid dish detergent & 18 & 6 & 7 & 0 & 892 & 6,112 & 34,530 & 2,589 & 3,051 \\
\hline Drinking water & 45 & 18 & 15 & 1 & $0 \quad 1,692$ & 14,852 & 71,019 & 13,541 & 23,752 \\
\hline Dry pasta & 93 & 9 & 4 & 1 & $1 \quad 1,504$ & 17,047 & 65,556 & 13,317 & 18,214 \\
\hline Dry fruit & 7 & 2 & 5 & 1 & 1323 & 2,707 & 12,423 & 1,098 & 1,271 \\
\hline Liquid fabric softener & 35 & 14 & 6 & 0 & 801 & 5,012 & 31,513 & 2,772 & 3,571 \\
\hline Face cosmetic & 7 & 5 & 4 & 0 & 238 & 1,744 & 8,714 & 622 & 775 \\
\hline Fillet & 5 & 4 & 3 & 1 & 76 & 543 & 2,594 & 240 & 189 \\
\hline Flour & 15 & 8 & 7 & 1 & 700 & 5,587 & 26,447 & 2,342 & 3,079 \\
\hline Liquid formula & 7 & 5 & 4 & 1 & 83 & 532 & 3,030 & 331 & 584 \\
\hline Powder formula & 32 & 3 & 4 & 1 & 320 & 3,683 & 13,821 & 2,621 & 4,223 \\
\hline Fresh cheese & 25 & 14 & 8 & 1 & 695 & 5,818 & 23,766 & 3,059 & 6,181 \\
\hline Fruit candy & 31 & 6 & 9 & 1 & 373 & 2,909 & 13,661 & 1,524 & 1,744 \\
\hline Fruit syrup & 10 & 5 & 7 & 1 & 174 & 1,303 & 6,826 & 573 & 684 \\
\hline Glass cleaner & 23 & 14 & 6 & 0 & 495 & 3,565 & 18,570 & 1,475 & 1,834 \\
\hline Packed ham & 4 & 2 & 3 & 1 & 97 & 672 & 3,379 & 229 & 417 \\
\hline Ice cream & 20 & 5 & 12 & 1 & 213 & 1,764 & 6,522 & 776 & 941 \\
\hline International meal & 7 & 3 & 5 & 1 & 120 & 963 & 3,228 & 279 & 447 \\
\hline Legume & 26 & 8 & 7 & 1 & 828 & 6,949 & 33,451 & 4,320 & 5,492 \\
\hline Mashed potato & 8 & 2 & 5 & 1 & 293 & 1,989 & 10,577 & 733 & 757 \\
\hline
\end{tabular}




\begin{tabular}{|c|c|c|c|c|c|c|c|c|c|c|}
\hline Mayonnaise & 10 & 6 & 4 & 1 & 1 & 408 & 2,805 & 15,049 & 1,201 & 1,494 \\
\hline Milk & 53 & 12 & 5 & 1 & 0 & 1,983 & 16,123 & 82,597 & 14,663 & 28,715 \\
\hline Fresh mushroom & 5 & 3 & 4 & 1 & 1 & 73 & 371 & 2,735 & 185 & 229 \\
\hline Napkin & 11 & 2 & 4 & 0 & 1 & 579 & 3,872 & 22,417 & 2,139 & 2,888 \\
\hline Nonalcoholic beer & 8 & 4 & 2 & 1 & 1 & 238 & 1,461 & 8,169 & 873 & 1,219 \\
\hline Nuts & 51 & 7 & 11 & 1 & 1 & 685 & 6,176 & 26,034 & 3,087 & 4,937 \\
\hline Oil & 38 & 13 & 6 & 1 & 1 & 1,386 & 9,817 & 58,464 & 7,132 & 11,124 \\
\hline Olive & 39 & 11 & 15 & 1 & 1 & 1,173 & 8,860 & 44,500 & 5,680 & 8,662 \\
\hline Palm fresh & 4 & 3 & 4 & 1 & 1 & 55 & 335 & 1,685 & 161 & 198 \\
\hline Paper towel & 9 & 4 & 5 & 0 & 1 & 1,246 & 7,751 & 48,676 & 4,802 & 5,904 \\
\hline Pate & 18 & 5 & 8 & 1 & 0 & 301 & 2,215 & 11,085 & 1,142 & 1,352 \\
\hline Peas fresh & 4 & 2 & 4 & 1 & 1 & 108 & 760 & 3,182 & 308 & 304 \\
\hline Pepper & 5 & 2 & 5 & 1 & 1 & 134 & 868 & 5,180 & 322 & 338 \\
\hline Pickle & 4 & 4 & 2 & 1 & 1 & 84 & 435 & 2,973 & 195 & 234 \\
\hline Pineapple juice & 15 & 9 & 3 & 1 & 0 & 427 & 2,911 & 15,712 & 1,740 & 2,790 \\
\hline Pizza & 25 & 4 & 9 & 1 & 0 & 515 & 4,958 & 18,795 & 3,040 & 4,718 \\
\hline Plastic bag & 19 & 3 & 8 & 0 & 1 & 1,170 & 8,521 & 45,179 & 4,706 & 5,644 \\
\hline Razor & 8 & 2 & 4 & 0 & 0 & 153 & 1,090 & 5,879 & 327 & 337 \\
\hline Rice & 25 & 9 & 4 & 1 & 1 & 1,133 & 7,678 & 44,520 & 4,298 & 5,720 \\
\hline RTE meal & 12 & 4 & 8 & 1 & 1 & 119 & 768 & 4,190 & 408 & 510 \\
\hline Vegetable salad & 6 & 5 & 4 & 1 & 1 & 190 & 1,379 & 6,330 & 528 & 1,412 \\
\hline Salt & 10 & 2 & 4 & 1 & 0 & 546 & 3,673 & 21,132 & 1,183 & 1,409 \\
\hline Sanitary napkin & 41 & 8 & 10 & 0 & 1 & 848 & 7,654 & 33,398 & 4,164 & 5,112 \\
\hline Liquid sauce & 13 & 8 & 7 & 1 & 0 & 239 & 1,759 & 8,927 & 618 & 758 \\
\hline Powder sauce & 25 & 15 & 18 & 1 & 0 & 239 & 1,734 & 8,211 & 736 & 1,001 \\
\hline Sausage & 12 & 8 & 9 & 1 & 1 & 103 & 878 & 3,163 & 208 & 374 \\
\hline Packed sausage & 22 & 7 & 15 & 1 & 1 & 392 & 3,126 & 13,151 & 1,482 & 2,102 \\
\hline Shampoo & 42 & 14 & 5 & 0 & 0 & 720 & 5,456 & 26,225 & 2,352 & 2,927 \\
\hline Shave cream & 9 & 7 & 3 & 0 & 0 & 128 & 832 & 4,475 & 227 & 228 \\
\hline Smoked fish & 7 & 2 & 3 & 1 & 1 & 102 & 876 & 3,698 & 248 & 412 \\
\hline Snack & 39 & 8 & 16 & 1 & 1 & 970 & 9,017 & 37,465 & 5,909 & 11,375 \\
\hline Soft drink & 95 & 20 & 10 & 1 & 0 & 376 & 4,062 & 16,640 & 3,581 & 6,642 \\
\hline Soup & 10 & 4 & 7 & 1 & 0 & 122 & 794 & 3,996 & 304 & 338 \\
\hline Spinach & 8 & 4 & 2 & 1 & 1 & 261 & 1,742 & 10,703 & 754 & 1,036 \\
\hline Sweet candy & 10 & 7 & 5 & 1 & 1 & 114 & 960 & 3,126 & 303 & 321 \\
\hline Tea & 20 & 4 & 6 & 1 & 0 & 208 & 1,529 & 7,056 & 581 & 778 \\
\hline Toilet paper & 12 & 3 & 6 & 0 & 1 & 1,539 & 9,692 & 60,521 & 6,540 & 8,827 \\
\hline Tomato juice & 4 & 3 & 2 & 1 & 0 & 94 & 534 & 2,829 & 223 & 255 \\
\hline Packed tomato & 32 & 12 & 17 & 1 & 1 & 1,216 & 9,153 & 48,732 & 6,002 & 8,940 \\
\hline Toothpaste & 46 & 22 & 6 & 0 & 0 & 732 & 5,529 & 27,440 & 2,553 & 3,172 \\
\hline Vinegar & 16 & 9 & 5 & 1 & 1 & 401 & 2,645 & 15,064 & 832 & 1,200 \\
\hline WC hygiene & 13 & 7 & 3 & 0 & 0 & 288 & 1,883 & 10,390 & 775 & 965 \\
\hline Female shave & 3 & 3 & 3 & 0 & 1 & 108 & 663 & 3,156 & 183 & 183 \\
\hline Stain remover & 4 & 3 & 3 & 0 & 0 & 119 & 614 & 4,438 & 205 & 278 \\
\hline Paper handkerchief & 8 & 4 & 4 & 0 & 1 & 600 & 4,342 & 23,385 & 2,084 & 2,653 \\
\hline Canned saltine & 9 & 6 & 2 & 1 & 0 & 119 & 719 & 4,232 & 345 & 355 \\
\hline Canned tuna & 26 & 8 & 8 & 1 & 0 & 1,140 & 7,843 & 43,617 & 4,955 & 6,831 \\
\hline Canned anchovy fillet & 6 & 6 & 3 & 1 & 0 & 112 & 872 & 3,724 & 241 & 360 \\
\hline Canned bonito & 12 & 5 & 10 & 1 & 0 & 196 & 1,307 & 6,932 & 770 & 1,058 \\
\hline Canned cockle & 15 & 8 & 7 & 1 & 0 & 301 & 2,075 & 9,622 & 813 & 962 \\
\hline Canned clams & 7 & 4 & 4 & 1 & 0 & 79 & 628 & 1,917 & 243 & 196 \\
\hline Canned mussel & 9 & 4 & 5 & 1 & 0 & 81 & 524 & 2,529 & 209 & 209 \\
\hline
\end{tabular}


Table $4 \quad$ Major Parameter Estimates of the Demand Model

\begin{tabular}{|c|c|c|c|c|c|c|c|c|}
\hline & \multicolumn{2}{|c|}{ Packed tomatoes } & \multicolumn{2}{|c|}{ Flour } & \multicolumn{2}{|c|}{ Liquid detergent } & \multicolumn{2}{|c|}{ Paper towel } \\
\hline & est & $\mathrm{se}$ & Est & $\mathrm{se}$ & Est & $\mathrm{se}$ & Est & $\mathrm{se}$ \\
\hline Light online shoppers & & & & & & & & \\
\hline Brand loyalty: online & 2.810 & .046 & 3.406 & .022 & 4.813 & .019 & 2.734 & .072 \\
\hline Brand loyalty: offline & 1.402 & .050 & 2.397 & .077 & 3.879 & .019 & 1.720 & .071 \\
\hline Size loyalty: online & 3.078 & .043 & 2.687 & .015 & 3.054 & .015 & 2.428 & .085 \\
\hline Size loyalty: offline & 2.124 & .039 & 1.934 & .019 & 2.398 & .012 & 1.698 & .059 \\
\hline Price: online & -2.842 & .024 & -6.163 & .048 & -0.576 & .014 & -2.285 & .051 \\
\hline Price: offline & -2.977 & .033 & -6.805 & .052 & -3.788 & .029 & -3.714 & .048 \\
\hline Moderate online shoppers & & & & & & & & \\
\hline Brand loyalty: online & 2.400 & .039 & 3.165 & .014 & 4.579 & .014 & 2.544 & .065 \\
\hline Brand loyalty: offline & 1.210 & .050 & 2.352 & .069 & 3.806 & .019 & 1.499 & .073 \\
\hline Size loyalty: online & 3.035 & .038 & 2.256 & .034 & 2.845 & .007 & 2.449 & .077 \\
\hline Size loyalty: offline & 2.005 & .042 & 1.798 & .036 & 1.866 & .026 & 1.509 & .059 \\
\hline Price: online & -3.107 & .019 & -6.961 & .026 & -1.467 & .006 & -2.648 & .044 \\
\hline Price: offline & -3.203 & .033 & -7.264 & .065 & -4.045 & .022 & -3.900 & .044 \\
\hline Heavy online shoppers & & & & & & & & \\
\hline Brand loyalty & 2.444 & .040 & 3.168 & .010 & 4.536 & .010 & 2.440 & .064 \\
\hline Brand loyalty: offline & 1.009 & .060 & 2.080 & .085 & 3.377 & .006 & 1.081 & .081 \\
\hline Size loyalty: online & 3.156 & .039 & 2.104 & .028 & 2.565 & .006 & 2.527 & .078 \\
\hline Size loyalty: offline & 1.667 & .051 & 1.949 & .040 & 1.844 & .010 & 1.168 & .065 \\
\hline Price: online & -3.269 & .019 & -6.584 & .030 & -1.086 & .008 & -2.613 & .046 \\
\hline Price: offline & -3.100 & .056 & -7.083 & .027 & -3.016 & .037 & -3.550 & .071 \\
\hline Demographics*brand loyalty & & & & & & & & \\
\hline Children*online & .043 & .010 & .099 & .049 & -0.026 & .024 & -.024 & .022 \\
\hline Elders*online & .153 & .009 & .289 & .078 & 0.143 & .024 & -.067 & .011 \\
\hline Family size*online & .287 & .013 & -.016 & .013 & 0.102 & .020 & .163 & .017 \\
\hline Distance*online & .273 & .029 & -.116 & .034 & -0.373 & .057 & .405 & .035 \\
\hline Children*offline & -.012 & .008 & -.033 & .037 & 0.025 & .020 & .011 & .028 \\
\hline Elders*offline & .139 & .008 & .131 & .028 & 0.002 & .019 & .014 & .011 \\
\hline Family size* offline & .300 & .011 & .071 & .019 & -0.103 & .017 & .184 & .017 \\
\hline Distance* offline & .749 & .025 & .090 & .032 & 0.388 & .056 & .403 & .048 \\
\hline Demographics*size loyalty & & & & & & & & \\
\hline Children*online & -.083 & .014 & -.203 & .051 & 0.088 & .023 & -.018 & .009 \\
\hline Elders*online & .362 & .013 & -.408 & .098 & 0.242 & .035 & .125 & .012 \\
\hline size*online & .284 & .013 & .109 & .024 & -0.110 & .019 & .198 & .018 \\
\hline Distance*online & .097 & .024 & -.136 & .034 & 0.376 & .066 & .471 & .042 \\
\hline Children*offline & -.111 & .013 & -.023 & .048 & 0.046 & .017 & -.111 & .035 \\
\hline Elders*offline & -.015 & .011 & -.188 & .048 & 0.061 & .022 & -.094 & .019 \\
\hline Family size ${ }^{*}$ of & .234 & .010 & .021 & .017 & 0.054 & .013 & .118 & .013 \\
\hline Distance*offline & .526 & .018 & -.057 & .033 & -0.248 & .042 & .544 & .044 \\
\hline Demographics*price & & & & & & & & \\
\hline Children*online & .055 & .008 & .055 & .009 & 0.116 & .030 & -.026 & .014 \\
\hline Elders*online & -.294 & .008 & -.549 & .018 & 1.244 & .011 & -.653 & .012 \\
\hline Family size* online & .282 & .005 & -.146 & .045 & -0.559 & .015 & .251 & .011 \\
\hline Distance*online & .850 & .014 & 1.258 & .027 & -1.042 & .023 & .556 & .021 \\
\hline Children*offline & .047 & .010 & -.236 & .016 & -0.174 & .014 & -.077 & .031 \\
\hline Elders*offline & -.038 & .011 & -.531 & .023 & 1.259 & .016 & -.620 & .012 \\
\hline Family size* offline & .220 & .006 & .026 & .046 & -0.407 & .016 & .367 & .010 \\
\hline Distance* offline & .792 & .022 & .184 & .134 & -0.853 & .009 & .893 & .028 \\
\hline
\end{tabular}


Table $5 \quad$ Online and Offline Elasticities

\begin{tabular}{l|rr|rr|rr|rr|rr}
\hline & \multicolumn{2}{|c|}{ Packed tomatoes } & \multicolumn{2}{|c|}{ Flour } & \multicolumn{2}{c|}{ Liquid detergent } & \multicolumn{2}{c}{ Paper towel } \\
\cline { 2 - 10 } & est & se & Est & se & Est & se & Est & se \\
\hline Light online shoppers & & & & & & & & \\
Brand loyalty: online & .590 & .018 & .412 & .017 & .288 & .009 & .867 & .042 \\
Brand loyalty: offline & .475 & .017 & .385 & .028 & .271 & .010 & .774 & .054 \\
Size loyalty: online & .510 & .014 & .496 & .031 & .674 & .035 & .804 & .044 \\
Size loyalty: offline & .436 & .013 & .354 & .027 & .572 & .025 & .665 & .044 \\
Price: online & -1.537 & .083 & -1.473 & .065 & -.911 & .030 & -1.471 & .170 \\
Price: offline & -2.092 & .110 & -1.706 & .088 & -1.662 & .029 & -2.711 & .189 \\
\hline Moderate online shoppers & & & & & & & & \\
Brand loyalty: online & .533 & .017 & .369 & .016 & .275 & .009 & .845 & .041 \\
Brand loyalty: offline & .429 & .017 & .356 & .026 & .263 & .009 & .710 & .054 \\
Size loyalty: online & .487 & .013 & .435 & .036 & .631 & .033 & .840 & .043 \\
Size loyalty: offline & .411 & .013 & .339 & .031 & .463 & .028 & .626 & .045 \\
Price: online & -1.968 & .075 & -1.685 & .060 & -1.165 & .028 & -2.012 & .160 \\
Price: offline & -2.504 & .108 & -1.823 & .090 & -1.741 & .026 & -3.093 & .183 \\
\hline Heavy online shoppers & & & & & & & & \\
Brand loyalty: online & .558 & .017 & .379 & .017 & .270 & .008 & .847 & .042 \\
Brand loyalty: offline & .420 & .020 & .328 & .029 & .241 & .009 & .619 & .060 \\
Size loyalty: online & .502 & .013 & .399 & .036 & .538 & .031 & .860 & .043 \\
Size loyalty: offline & .348 & .013 & .363 & .032 & .426 & .023 & .549 & .048 \\
Price: online & -2.201 & .076 & -1.613 & .063 & -1.054 & .029 & -1.975 & .161 \\
Price: offline & -2.311 & .142 & -1.786 & .080 & -1.474 & .032 & -2.543 & .223 \\
\hline
\end{tabular}

Table 6

Summary of Brand Loyalty, Size Loyalty and Price Elasticities

\begin{tabular}{|c|c|c|c|c|c|c|}
\hline & $>0$ & $<0$ & \multicolumn{2}{|c|}{ Online $>$ offline } & \multicolumn{2}{|c|}{ Online < offline } \\
\hline Light online shoppers & & & \# & $\%$ & \# & $\%$ \\
\hline Brand loyalty: online & 93 & 0 & 83 & 89.24 & 10 & 10.76 \\
\hline Brand loyalty: offline & 93 & 0 & & & & \\
\hline Size loyalty: online & 93 & 0 & 83 & 89.24 & 10 & 10.76 \\
\hline Size loyalty: offline & 93 & 0 & & & & \\
\hline Price elasticity & 0 & 93 & 93 & 100.00 & 0 & 0.00 \\
\hline Moderate online shoppers & & & & & & \\
\hline Brand loyalty: online & 93 & 0 & 79 & 84.95 & 14 & 15.05 \\
\hline Brand loyalty: offline & 93 & 0 & & & & \\
\hline Size loyalty: online & 93 & 0 & 82 & 88.17 & 11 & 11.83 \\
\hline Size loyalty: offline & 93 & 0 & & & & \\
\hline Price elasticity & 0 & 93 & 84 & 90.32 & 10 & 9.68 \\
\hline Heavy online shoppers & & & & & & \\
\hline Brand loyalty: online & 93 & 0 & 80 & 86.02 & 13 & 13.98 \\
\hline Brand loyalty: offline & 93 & 0 & & & & \\
\hline Size loyalty: online & 93 & 0 & 82 & 88.17 & 11 & 11.83 \\
\hline Size loyalty: offline & 93 & 0 & & & & \\
\hline Price elasticity & 0 & 93 & 65 & 69.89 & 28 & 31.11 \\
\hline
\end{tabular}


Table 7 Correlation between Online and Offline Brand Loyalty, Size Loyalty \& Price Sensitivity

\begin{tabular}{|c|c|c|c|c|c|c|c|}
\hline & $\begin{array}{l}\text { Online } \\
\text { Brand } \\
\text { Loyalty }\end{array}$ & $\begin{array}{l}\text { Offline } \\
\text { Brand } \\
\text { Loyalty }\end{array}$ & $\begin{array}{l}\text { Online } \\
\text { Size } \\
\text { Loyalty }\end{array}$ & $\begin{array}{l}\text { Offline } \\
\text { Size } \\
\text { Loyalty }\end{array}$ & \multicolumn{2}{|c|}{$\begin{array}{l}\mid \text { Online } \\
\text { Price } \\
\text { Sensitivity }\end{array}$} & ine \\
\hline \multicolumn{8}{|l|}{ Light online shoppers } \\
\hline Online brand loyalty & 1 & & & & & & \\
\hline Offline brand loyalty & $.919 * * *$ & 1 & & & & & \\
\hline Online size loyalty & .100 & $.231 * *$ & 1 & & & & \\
\hline Offline size loyalty & $.204 * *$ & $.298 * * *$ & $.914 * * *$ & 1 & & & \\
\hline |Online price sensitivity| & $.217 * *$ & $.222 * *$ & $.269 * * *$ & $.239 * *$ & 1 & & \\
\hline |Offline price sensitivity| & $.187 *$ & $.200 *$ & $.283 * * *$ & $.281 * * *$ & $.974 * *$ & & 1 \\
\hline \multicolumn{8}{|l|}{ Moderate online shoppers } \\
\hline Online brand loyalty & 1 & & & & & & \\
\hline Offline brand loyalty & $.947 * * *$ & 1 & & & & & \\
\hline Online size loyalty & $.247 * *$ & $.308 * * *$ & 1 & & & & \\
\hline Offline size loyalty & $.284 * * *$ & $.322 * * *$ & $.867 * * *$ & 1 & & & \\
\hline |Online price sensitivity| & .169 & .112 & $.251 * *$ & $.234 * *$ & 1 & & \\
\hline |Offline price sensitivity| & $.188 *$ & .149 & $.290 * * *$ & $.328 * * *$ & $.971 * *$ & & 1 \\
\hline \multicolumn{8}{|l|}{ Heavy online shoppers } \\
\hline Online brand loyalty & 1 & & & & & & \\
\hline Offline brand loyalty & $.934 * * *$ & 1 & & & & & \\
\hline Online size loyalty & $.215^{* *}$ & $.236 * *$ & 1 & & & & \\
\hline Offline size loyalty & $.255^{* *}$ & $.226 * *$ & $.823 * * *$ & 1 & & & \\
\hline \multirow{2}{*}{ |Online price sensitivity| } & .166 & .126 & .171 & $.194 *$ & 1 & & \\
\hline & .156 & .126 & .118 & .140 & $.981 * *$ & & 1 \\
\hline All households & & & & & & & \\
\hline Online brand loyalty & 1 & & & & & & \\
\hline Offline brand loyalty & $.923 * * *$ & 1 & & & & & \\
\hline Online size loyalty & $.180 * * *$ & $.254 * * *$ & 1 & & & & \\
\hline Offline size loyalty & $.247 * * *$ & $.279 * * *$ & $.867 * * *$ & 1 & & & \\
\hline Online price sensitivity & $.182 * * *$ & $.149 * *$ & $.223 * * *$ & $.215 * * *$ & 1 & & \\
\hline Offline price sensitivity & $.177 * * *$ & $.156^{* * *}$ & $.231 * * *$ & $.257 * *$ & $.970 * *$ & & 1 \\
\hline Table 8 & T-test 0 & Online and & Offline $\mathrm{R}$ & tios (test & alue $=1)$ & & \\
\hline & & $\mathrm{N}$ & Mean & $\mathrm{Sd}$ & $\mathrm{Se}$ & t-stat & \\
\hline Brand loyalty ratio (o & ine/offline & & & & & & \\
\hline All shoppers & & 279 & 1.318 & 0.688 & 0.041 & 7.714 & \\
\hline Light online shopp & & 93 & 1.422 & 0.993 & 0.103 & 4.105 & \\
\hline Moderate online st & ppers & 93 & 1.209 & 0.254 & 0.026 & 7.939 & \\
\hline Heavy online shop & & 93 & 1.322 & 0.598 & 0.062 & 5.197 & \\
\hline Size loyalty ratio (onl & e/offline) & & & & & & \\
\hline All shoppers & & 279 & 1.364 & 0.537 & 0.032 & 11.330 & \\
\hline Light online shopp & & 93 & 1.342 & 0.503 & 0.052 & 6.559 & \\
\hline Moderate online sh & ppers & 93 & 1.364 & 0.623 & 0.065 & 5.636 & \\
\hline Heavy online shop & & 93 & 1.385 & 0.477 & 0.050 & 7.784 & \\
\hline Price sensitivity ratio & nline/offli & & & & & & \\
\hline All shoppers & & 279 & 0.820 & 0.265 & 0.016 & -11.380 & \\
\hline Light online shopp & & 93 & 0.698 & 0.243 & 0.025 & -12.036 & \\
\hline Moderate online sh & ppers & 93 & 0.823 & 0.220 & 0.023 & -7.776 & \\
\hline Heavy online shop & & 93 & 0.940 & 0.274 & 0.028 & -2.120 & \\
\hline
\end{tabular}


Regression of within-channel Elasticities on Household Characteristics

\begin{tabular}{|c|c|c|c|c|c|c|c|c|}
\hline & \multicolumn{2}{|c|}{ Online } & \multicolumn{2}{|c|}{ Offline } & \multicolumn{2}{|c|}{ Online } & \multicolumn{2}{|c|}{ Offline } \\
\hline & est & se & est & se & est & se & est & se \\
\hline Brand loyalty & & & & & & & & \\
\hline Light online shoppers & .049 & .030 & .046 & .024 & .073 & .034 & .050 & .027 \\
\hline Moderate online shoppers & .001 & .030 & -.005 & .024 & .002 & .034 & .018 & .027 \\
\hline No. of preschool children & & & & & .245 & .144 & -.234 & .116 \\
\hline No of elders & & & & & .459 & .358 & -.068 & .290 \\
\hline Family size & & & & & -.242 & .098 & .201 & .079 \\
\hline Closest distance & & & & & -.450 & .332 & -.051 & .268 \\
\hline $\mathrm{N}$ & 279 & & 279 & & 279 & & 279 & \\
\hline $\mathrm{R}^{2}$ & .981 & & .978 & & .982 & & .980 & \\
\hline Size loyalty & & & & & & & & \\
\hline Light online shoppers & .080 & .041 & .094 & .037 & .084 & .044 & .071 & .037 \\
\hline Moderate online shoppers & .029 & .041 & .059 & .037 & .023 & .044 & .090 & .037 \\
\hline No. of preschool children & & & & & -.727 & .190 & -.334 & .160 \\
\hline No of elders & & & & & -.797 & .472 & .415 & .398 \\
\hline Family size & & & & & .411 & .129 & .486 & .109 \\
\hline Closest distance & & & & & 1.398 & .437 & 1.340 & .369 \\
\hline $\mathrm{N}$ & 279 & & 279 & & 279 & & 279 & \\
\hline $\mathrm{R}^{2}$ & .964 & & .947 & & .969 & & .960 & \\
\hline Price elasticity & & & & & & & & \\
\hline Light online st & .456 & .055 & -.140 & .059 & .473 & .063 & -.092 & .065 \\
\hline Moderate online shoppers & .052 & .055 & -.256 & .059 & .034 & .063 & -.275 & .065 \\
\hline No. of preschool children & & & & & -.035 & .270 & -.190 & .279 \\
\hline No of elders & & & & & -.925 & .672 & .112 & .694 \\
\hline Family size & & & & & .011 & .184 & -.493 & .190 \\
\hline Closest distance & & & & & -.380 & .623 & -1.560 & .643 \\
\hline $\mathrm{N}$ & 279 & & 279 & & 279 & & 279 & \\
\hline $\mathrm{R}^{2}$ & .994 & & .994 & & .994 & & .995 & \\
\hline
\end{tabular}

* Category fixed effects are not reported. Results account for sampling errors in the elasticities.

Table 10 Regression of Loyalty \& Price Elasticities on Product \& Household Characteristics

\begin{tabular}{l|rrr|rrr|rrr}
\hline \multirow{2}{*}{} & \multicolumn{3}{|c|}{ Brand loyalty } & \multicolumn{3}{c|}{ Size loyalty } & \multicolumn{3}{c}{ Price Elasticity } \\
\cline { 2 - 10 } & est & se & t-stat & est & se & t-stat & est & se & t-stat \\
\hline Sood*online & .094 & .033 & 2.837 & .184 & .038 & 4.789 & .086 & .051 & 1.680 \\
Light online shoppers*online & .072 & .037 & 1.940 & .042 & .043 & .979 & .312 & .069 & 4.535 \\
Moderate online shoppers*online & .120 & .032 & 3.709 & .066 & .037 & 1.759 & .556 & .060 & 9.316 \\
No. of preschool children & .073 & .032 & 2.263 & .085 & .037 & 2.275 & .112 & .060 & 1.885 \\
No of elders & .033 & .114 & .292 & -.511 & .132 & -3.868 & -.026 & .211 & -.125 \\
Family size & .221 & .287 & .770 & -.213 & .332 & -.640 & -.137 & .530 & -.259 \\
Closest distance & -.012 & .078 & -.152 & .442 & .091 & 4.859 & -.153 & .145 & -1.054 \\
$\mathrm{~N}$ & -.393 & .246 & -1.595 & 1.294 & .286 & 4.529 & -1.535 & .456 & -3.367 \\
\hline $\mathrm{R}^{2}$ & 558 & & & 558 & & & 558 & & \\
\hline
\end{tabular}

* Category fixed effects are not reported. 
Table $11 \quad$ Summary of Findings and Implications

\begin{tabular}{|c|c|}
\hline Findings & Implications \\
\hline $\begin{array}{l}\text { The same households are more brand loyal, } \\
\text { more size loyal, but less price sensitive in } \\
\text { the online store than in the offline stores. }\end{array}$ & $\begin{array}{l}\text { The retailer can fine tune its pricing policies for } \\
\text { the two channels and charge price premiums in the } \\
\text { online store. }\end{array}$ \\
\hline $\begin{array}{l}\text { Light online shoppers are least price } \\
\text { sensitive and heavy online shoppers are } \\
\text { most price sensitive in the online store. } \\
\text { Moderate online shoppers are most price } \\
\text { sensitive in the offline stores. }\end{array}$ & $\begin{array}{l}\text { The retailer can adopt differential and targeted } \\
\text { promotions for different types of households: } \\
\text { - Deeper online coupon drops for heavy online } \\
\text { shoppers } \\
\text { - Deeper offline coupon drops for moderate } \\
\text { online shoppers } \\
\text { - Promote the online store to light online } \\
\text { shoppers and non-online shoppers }\end{array}$ \\
\hline $\begin{array}{l}\text { Online and offline differences in brand } \\
\text { loyalty and price sensitivity are larger for } \\
\text { food products than for non-food products } \\
\text { and larger for sensory products than for non- } \\
\text { sensory products. }\end{array}$ & $\begin{array}{l}\text { - Offer more non-food products and non-sensory } \\
\text { products in the online store } \\
\text { - Offer more food products and more sensory } \\
\text { products in the offline stores } \\
\text { - Charge price premiums for food products and } \\
\text { sensory products in the online store }\end{array}$ \\
\hline
\end{tabular}




\section{Appendix Results of Random Coefficients Logit}

Table A1 T-test of Online and Offline Ratios (test value=1): Random Coefficients Logit

\begin{tabular}{lrrrrr}
\hline & $\mathrm{N}$ & Mean & \multicolumn{1}{c}{$\mathrm{Sd}$} & $\mathrm{Se}$ & \multicolumn{1}{c}{ t-stat } \\
\hline Brand loyalty ratio (online/offline) & & & & & \\
$\quad$ All shoppers & 99 & 1.437 & 1.087 & .109 & 4.005 \\
$\quad$ Light online shoppers & 33 & 1.645 & 1.613 & .281 & 2.295 \\
$\quad$ Moderate online shoppers & 33 & 1.266 & .698 & .122 & 2.188 \\
$\quad$ Heavy online shoppers & 33 & 1.401 & .671 & .117 & 3.437 \\
\hline Size loyalty ratio (online/offline) & & & & & \\
$\quad$ All shoppers & 99 & 1.271 & .495 & .050 & 5.451 \\
Light online shoppers & 33 & 1.262 & .486 & .085 & 3.091 \\
Moderate online shoppers & 33 & 1.201 & .297 & .052 & 3.884 \\
Heavy online shoppers & 33 & 1.350 & .643 & .112 & 3.128 \\
\hline Price sensitivity ratio (online/offline) & & & & & \\
All shoppers & 99 & 0.746 & 0.245 & 0.025 & -10.337 \\
$\quad$ Light online shoppers & 33 & 0.652 & 0.265 & 0.046 & -7.535 \\
Moderate online shoppers & 33 & 0.778 & 0.196 & 0.034 & -6.510 \\
Heavy online shoppers & 33 & 0.807 & 0.246 & 0.043 & -4.513 \\
\hline
\end{tabular}

Table A2 Regression of within-channel Elasticities on Household Characteristics

\begin{tabular}{|c|c|c|c|c|c|c|c|c|}
\hline & \multicolumn{2}{|c|}{ Online } & \multicolumn{2}{|c|}{ Offline } & \multicolumn{2}{|c|}{ Online } & \multicolumn{2}{|c|}{ Offline } \\
\hline & est & $\mathrm{se}$ & est & se & est & se & est & $\mathrm{se}$ \\
\hline Brand loyalty & & & & & & & & \\
\hline Light online shoppers & .222 & .127 & .157 & .088 & .040 & .068 & .136 & .077 \\
\hline Moderate online shoppers & .213 & .127 & .044 & .089 & .136 & .069 & .050 & .079 \\
\hline No. of preschool children & & & & & .250 & .215 & .069 & .245 \\
\hline No of elders & & & & & .475 & .570 & .699 & .650 \\
\hline Family size & & & & & -.328 & .158 & -.420 & .180 \\
\hline Closest distance & & & & & .444 & .507 & -.228 & .578 \\
\hline $\mathrm{N}$ & 99 & & 99 & & 99 & & 99 & \\
\hline $\mathrm{R}^{2}$ & .975 & & .946 & & .977 & & .951 & \\
\hline Size loyalty & & & & & & & & \\
\hline Light online shoppers & .233 & .110 & .195 & .120 & .110 & .099 & .101 & .062 \\
\hline Moderate online shoppers & .200 & .110 & .169 & .120 & .058 & .101 & .053 & .063 \\
\hline No. of preschool children & & & & & -.286 & .315 & .022 & .196 \\
\hline No of elders & & & & & .090 & .833 & 1.051 & .521 \\
\hline Family size & & & & & .144 & .231 & .030 & .144 \\
\hline Closest distance & & & & & -.129 & .741 & -.004 & .463 \\
\hline $\mathrm{N}$ & 99 & & 99 & & 99 & & 99 & \\
\hline $\mathrm{R}^{2}$ & .945 & & .964 & & .947 & & .969 & \\
\hline Price elasticity & & & & & & & & \\
\hline Light online shoppers & .711 & .181 & -.130 & .242 & .636 & .200 & .029 & .184 \\
\hline Moderate online shoppers & .209 & .181 & -.441 & .242 & .132 & .205 & -.330 & .189 \\
\hline No. of preschool children & & & & & -1.175 & .637 & -.606 & .586 \\
\hline No of elders & & & & & -1.452 & 1.687 & -.240 & 1.553 \\
\hline Family size & & & & & .099 & .467 & -.655 & .430 \\
\hline Closest distance & & & & & .082 & 1.501 & .323 & 1.381 \\
\hline $\mathrm{N}$ & 99 & & 99 & & 99 & & 99 & \\
\hline $\mathrm{R}^{2}$ & .986 & & .990 & & .987 & & .991 & \\
\hline
\end{tabular}

\footnotetext{
$*$ Category fixed effects are not reported.
} 
Table A3 Regression of Loyalty \& Price Elasticities on Product \& Household Characteristics

\begin{tabular}{l|rrr|rrr|rrr}
\hline & \multicolumn{3}{|c|}{ Brand loyalty } & \multicolumn{3}{c|}{ Size loyalty } & \multicolumn{3}{c}{ Price Elasticity } \\
\cline { 2 - 11 } & \multicolumn{1}{|c|}{ est } & se & t-stat & est & se & t-stat & est & se & t-stat \\
\hline Food*online & .142 & .077 & 1.847 & .148 & .075 & 1.983 & .262 & .189 & 1.387 \\
Sensory*online & .057 & .064 & .888 & .081 & .082 & .993 & .640 & .206 & 3.108 \\
Light online shoppers*online & .092 & .051 & 1.793 & .054 & .049 & 1.100 & .625 & .174 & 3.582 \\
Moderate online shoppers*online & .004 & .052 & .076 & .018 & .050 & .365 & .106 & .176 & .603 \\
No. of preschool children & .205 & .184 & 1.115 & -.132 & .179 & -.737 & -.905 & .451 & -2.006 \\
No of elders & .643 & .491 & 1.308 & .588 & .477 & 1.232 & -.689 & 1.203 & -.573 \\
Family size & -.345 & .135 & -2.548 & .092 & .132 & .702 & -.234 & .332 & -.706 \\
Closest distance & -.204 & .411 & -.496 & -.099 & .399 & -.248 & -.004 & 1.006 & -.004 \\
$\mathrm{~N}$ & 198 & & & 198 & & & 198 & & \\
\hline $\mathrm{R}^{2}$ & .974 & & & .983 & & & .984 & & \\
\hline
\end{tabular}

* Category fixed effects are not reported. 